Investigaciones Fenomenológicas, n. 9, 2012, 431-471.

e-ISSN: $1885-1088$

\title{
ARQUITECTÓNICA Y CONCRESCENCIA. \\ Prolegómenos a una aproximación mereológica de LA ARQUITECTÓNICA FENOMENOLÓGICA
}

\author{
Pablo Posada Varela \\ Université Paris IV-Sorbonne, Francia / \\ Bergische Universität Wuppertal, Alemania \\ pabloposadavarela @gmail.com
}

\begin{abstract}
Resumen: Este artículo trata de sentar las bases de una aproximación arquitectónica a la mereología. A tal fin elaboramos un acercamiento intuitivo (y literario) a la idea de concreción fenomenológica y a la estructura del fenómeno en sentido fenomenológico, accediendo a una primera noción, provisional, de lo que habrían de ser las concrescencias hiperbólicas. Nos centramos luego en la teoría transcendental del método, habiéndonoslas con una primera comparecencia del Genio Maligno. En una última parte tratamos de elucidar el sentido de la arquitectónica como parte de la teoría transcendental del método.
\end{abstract}

Palabras clave: Fenómeno, concreción, mereología, arquitectónica, concrescencia, hipérbole, fenomenologizar, genio maligno, Husserl, Fink, Richir, Ramón Gómez de la Serna, José Bergamín.

\begin{abstract}
The aim of this paper is to settle down the basis for an architectonical approach of mereology. In this regard, we begin by developing, in the very first part of the present work, an intuitive (and literary) approach to the idea of phenomenological concreteness, as well as to the structure of the phenomenon in a genuine phenomenological sense. We then come up with a first, provisory notion, of what hyperbolic concrescences ought to be. We then focus on the transcendental theory of method and deal with a first occurrence of the Malignant Demon. In the last part of this paper, we try to shed some light on the sense of architectonics as a part of the transcendental theory of method.
\end{abstract}

Keywords: Phenomenon, concreteness, mereology, architectonics, concrescence, hyperbole, phenomenologizing, Genius Malignus, Husserl, Fink, Richir, Ramón Gómez de la Serna, José Bergamín.

En el presente artículo trato de sentar las bases fenomenológicas de un tratamiento mereológico de la reducción transcendental y de la epojé fenomenológica hiperbólica. Este trabajo constituye una suerte de introducción a otro, re- 
cientemente publicado ${ }^{1}$, y que sería algo así como la continuación o, al menos, una posible continuación de lo que aquí intentamos.

Este artículo elabora, en lo fundamental, un acercamiento intuitivo a la cuestión de la concreción (de las concretudes y de la concrescencia). El texto se divide en varios párrafos, con encabezamientos temáticos, que, creo, facilitan su comprensión, que guían mejor la lectura.

Por otro lado, y a pesar de contar este número de Investigaciones fenomenológicas con textos de Richir, nos ha parecido más interesante guardarnos de elaborar una presentación o introducción más a su fenomenología ${ }^{2}$. O acaso

\footnotetext{
${ }^{1}$ Este artículo es una suerte de prolegómeno fenomenológico y metodológico a otro artículo, a saber, "Concrétudes en concrescences", publicado en la revista Annales de Phénoménologie 11 (2012) 756. www.annalesdephenomenologie.org.

Los "prolegómenos" que representan estas líneas buscan, en el fondo, hacer más legible el artículo "Concrétudes en concrescences", ya publicado. Artículo que volveremos a reelaborar en breve bajo la forma de otra posible segunda parte del presente trabajo. He ahí la motivación fundamental de las líneas que siguen. Así, tanto ese trabajo de próxima publicación como, sobre todo, las presentes líneas, responden a discusiones, muy valiosas para mí, que pedían no pocas aclaraciones relativas al citado trabajo "Concrétudes en concrescences".

Huelga decir que estas líneas deben mucho (como mi texto, por otro lado, da a entender) a la fenomenología del propio Marc Richir, así como a las múltiples discusiones, con él, sobre estos temas. También a Miguel García-Baró y a Agustín Serrano de Haro, a los que debo la perspectiva mereológica de muchos de mis análisis. Muy en especial al libro de Agustín Serrano de Haro, Fenomenología trascendental y ontología (Madrid, Servicio de Publicaciones de la Universidad Complutense de Madrid, 1991), que sigue siendo para mí una continua fuente de inspiración, y uno de los mejores libros sobre la fenomenología de Husserl que yo conozca. No quisiera olvidar tampoco el salto cualitativo que para mí supuso, en la comprensión de la fenomenología de Richir, el encuentro, hará algo más de dos años, con Ricardo Sánchez Ortiz de Urbina, y la forma, originalísima, con la que reasume desde un enfoque propio algunos elementos de la fenomenología de Richir.

Este artículo se ha beneficiado de la lectura atenta y generosa de Javier Arias Navarro, lectura llena de sugerencias formales y estilísticas valiosísimas, y llena de muchas otras, relativas al contenido, a su elaboración y profundización que, por falta de tiempo, no he podido asumir, pero que ahí quedan para futuros desarrollos.

Por último, mi gratitud va a Iván Galán Hompanera (también por la lectura de una última versión y su ayuda en no pocas correcciones formales), a Sacha Carlson y a Thomas Maurice. A los tres por las muchas discusiones y comentarios que, surgidos a raíz del artículo "Concrétudes en concrescences", han permitido que este texto haya ido madurando y mejorando dentro de los límites que, claro está, son los propios.

Este artículo, así como otras contribuciones (bajo la forma de traducciones) hechas a este número 9 de Investigaciones Fenomenológicas han estado generosísimamente alentadas por los ánimos y el apoyo de la profesora María-Luz Pintos Peñaranda. Vaya desde estas líneas mi más sincero agradecimiento por su comprensión, su buena disposición, su eficacia y diligencia y su profunda humanidad, cualidades todas ellas que, como digo, han amparado y sostenido el esfuerzo requerido para llevar a buen término -y plazo- todas estas contribuciones.

${ }^{2}$ En Eikasia 34 (2010) y Eikasia 40 (2011), www.revistadefilosofia.com, pueden ya encontrarse multitud de presentaciones, en español, de la fenomenología de Marc Richir. Cumple también señalar la extraordinaria página web montada por Sacha Carlson: www.laphenomenologierichirienne.org con multitud de artículos disponibles, artículos de y sobre Richir, e incluso algunos libros del propio Richir. En espera de la tesis doctoral de Sacha Carlson, codirigida por Guy van Kerckhoven, que trata sobre el conjunto de la obra de Richir con una profundidad, precisión y exhaustividad hasta ahora inauditas en el panorama de la bibliografía richiriana, podemos remitir a su excelente trabajo, publicado en el número 34 de Eikasia y por lo tanto disponible en línea: Sacha Carlson: "L'essence du phénomène. La pensée de Marc Richir face à la tradition phénoménologique".pdf (Tesina, Universidad Católica de Lovaina -Louvainla-Neuve-1997). También puede consultarse, creo que con provecho, la siguiente presentación general de la fenomenología de Richir: Pablo Posada Varela, "En torno a la singladura filosófica y fenomenológica de Marc Richir".pdf, Eikasia 40 (2011). Remitimos también, obviamente, a los trabajos de Ricardo Sánchez Ortiz de Urbina que es, a mi parecer y hasta donde yo sé, el más profundo conocedor (no sólo en el mundo de habla hispana) de la obra de Richir.
} 
precisamente por ello, pues esos textos de Richir cumplen la labor de introducción bastante mejor de lo que yo mismo pudiera hacerlo. En cualquier caso, quizá no esté de más aclarar, por desbaratar de entrada toda falsa expectativa, que el presente texto, inspirado en ciertos elementos de la fenomenología de Richir, no es, en primer término, una presentación de la misma, lo cual no quiere decir que algunos puntos de ésta no se aclaren a la luz de lo que aquí decimos. Acaso tanto más por hacerlo con un lenguaje ligeramente distinto.

"iA las cosas mismas!" proclamaba Husserl. Tras lo que a simple vista pudiera parecer una trivialidad se esconde algo muy preciso $y$, al tiempo, difícil de captar. ¿De qué se trata y por qué no estamos, como sería de justicia sospechar, ante una simple y llana perogrullada?

Sabemos, para empezar, que "cosa" traduce "Sache" y no "Ding". Así, la "cosa" del lema preconizado por Husserl estaría entre la "cosa" tal como suele entenderse (las cosas "palpables", "contantes y sonantes") y el "asunto". El "asunto" es lo que nos ocupa y requiere como lo hace una "causa" en su más amplio y primigenio sentido. Sentido que, precisamente, no es el epistemológico. Los "asuntos" son lo que nos concierne y ocupa (ta pragmata), son lo que, incluso, nos compromete. No son, pues, asuntos en que alienten "causas" vacuas y lejanas, sino "causas" insistentes y palpables, tan palpables como las "cosas". Se trata, en suma, de pensar el "asunto", el carácter de "asunto", la Sachlichkeit, como algo concreto (a lo que el sentido del término alemán sí hace mayor justicia). Pero, ¿de qué concreción se trata? ¿En qué se desvía de la burda concreción de la cosa entendida como cosa física, palpable?

\section{DeL LADO DE LA TEORÍA TRANSCENDENTAL DE LOS ELEMENTOS: ¿QUÉ SON LAS "COSAS MISMAS" DE LA FENOMENOLOGÍA?}

La pregunta que encabeza este epígrafe no es, efectivamente, cuestión fácil de dirimir. Los asuntos hechos cosa son insistentes, pregnantes y, con todo, ilocalizables. Parecen renuentes, en su estructura misma, a hallar localización según coordenadas. Efectivamente, las cosas de la fenomenología son renuentes ya desde su estructura. Lo son porque -adelantémoslo en aras a la inteligibilidad del texto- dicha estructura incluye una parte subjetiva (en coalescencia con una parte objetiva). Parte subjetiva en la que, además y por si no fuera 
poco (es decir: dicho a mayor abundancia en la complejidad y relieve estructurales de lo que aquí está en juego) el yo que filosofa, o el yo que hace fenomenología (yo fenomenologizante ${ }^{3}$ ), se halla también involucrado.

Hay, pues, una suerte de cascada fluctuante de coalescencias; cascada, por lo demás, con tramos que, encontrándose a niveles diferentes, parecen solaparse. Ni se dejan éstos poner partes extra partes, ni tampoco alinearse fácilmente en un mismo plano; de ahí que un "objeto" - dicho en sentido lato, como quien dice "objeto de estudio"- de ese cariz -i.e., del cariz de las "cosas" o "asuntos" de la fenomenología-, un "objeto" tocado con esa estructura (compleja y no sencilla de alisar y luego compartimentar), sea tan difícil de situar, de abatir sobre un plano y de cercar con arreglo a coordenadas. Efectivamente, parece que la estructura de fenómeno, de concretudes en concrescencia, es, en parte por los motivos estructurales que acabamos de aducir, ínsitamente refractaria a toda localización en un espacio-tiempo objetivo. Y nada arreglaría, por cierto, multiplicar las dimensiones. Por muchas que éstas sean, toda localización -así se multipliquen los ejes de coordenadas- no deja de ser extrínseca, y no observa -sino que fuerza- dos dificultades estructurales fundamentales con las que la fenomenología ha de bregar para capturar y estabilizar sus "cosas mismas".

De un lado, con la dificultad inherente a que el fenomenologizar se mueve en una relación de identidad con el yo transcendental ${ }^{4}$, por lo que el yo del discurso no está fuera del plano de proyección, sino que es también objeto de estudio y, como veremos, materia de concrescencia. Los tramos de vida transcendental fenomenologizante son, quiérase o no, parte contraída o "contratante" de esas concrescencias en que consisten las "cosas mismas" de la fenomenología. Tan profundas son "esas cosas" que su pinza de concrescencia va hasta contraer a concrescencia una parte (de la parte) fenomenologizante; parte, a su vez, de la vida transcendental.

\footnotetext{
${ }^{3}$ El concepto es, como se sabe, de Eugen Fink, y juega un papel esencial en su Sexta Meditación Cartesiana: Eugen Fink, VI Cartesianische Meditation. Teil I: Die Idee einer transzendentalen Methodenlehre, Dordrecht, Kluwer Academic Publishers, 1988. Editado por Jann Holl Ebeling y Guy van Kerhoven.

${ }^{4}$ Cfr. Ibidem, $\S \S 1$ y 2.
} 
De otro, a la fenomenología repugna toda localización hecha sobre fondo de mundo. Ello se cobra, como veremos ${ }^{5}$, una suerte de aplastamiento que no se compadece con la idea de concreto propia de los fenómenos de la fenomenología. La concrescencia entre las partes del fenómeno de la fenomenología requiere una suspensión de todo fondo de mundo y una "mereologización" de los operadores de inclusión y pertenencia. Un concreto que incluya en sí mismo, junto a sus partes constituidas (que aparecen en inherencia intencional), partes transcendentales (constituyentes) ${ }^{6}$, no es tal cual depositable en, digamos, fondo-de-mundo, en un todo en general o en ese todo englobante cuyo fondo es el mundo. No es depositable "tal cual", es decir: sin sufrir variación en su sentido, erosión en sus relieves. Ello sin contar -lo que complica aún más las cosas - con las "partes" fenomenologizantes: tramos de vida fenomenologizante pertenecientes, a su vez, a la vida transcendental, pero arquitectónicamente difractados de ésta.

La tensión de concrescencia de todas estas partes de la concreción fenomenológica se dispara, precisamente, por la espita de la insólita suspensión de una adscripción de la experiencia a un fondo de mundo. Por la espita de la (imposible) universalización de la epojé termina abriéndose paso la reducción. La epojé empieza por suspender esa adscripción que asegura de antemano -por las vías de la inclusión y la pertenencia- el rendimiento de dicha concrescencia. Asegura de antemano ese estar juntos, ese ser articulaciones de una pieza, que la concrescencia ya siempre ha rendido en propio, inconsútilmente rendido: sin partes que sean, a su vez, costuras. Propiedad de rendimiento (ésa de la concrescencia) que, así, aperceptivamente asegurada de antemano, queda sepultada. La epojé obra una suerte de cortocircuito; la reducción aporta, más bien, la sostenibilidad de ese cortocircuito mediante una derivación. La epojé constituye, pues, esa suerte de Aus-schlatung contra-aperceptiva por la que se comete la osadía, la insensatez, la insolencia (ante el Mundo, ante su imponente verdad) de una desconexión radical. Esa desconexión deja franca, franca para la reducción, una insólita espita de vida transcendental desde la cual derivar la

\footnotetext{
${ }^{5}$ Sobre todo, y de modo enteramente explícito, en la anunciada segunda parte de este artículo. En su defecto, el lector puede remitirse a Pablo Posada Varela, "Concrétudes en concrescences", art. cit. in supra, nota 1.

${ }^{6} \mathrm{Cfr}$. sobre este punto y, en general, sobre todas las referencias a la mereología contenidas en estas líneas: Agustín Serrano de Haro, op. cit.

7 Es, sin embargo, esencial tener en cuenta este problema a la hora de captar la especificidad de lo que Ilamaremos las "concrescencias hiperbólicas".
} 
entera corriente de la Schaltung transcendental; corriente otrora rebotada por entre los perdederos de la actitud natural, perdederos balizados por los mojones auto-aperceptivos que configuran la apercepción mundanizante, suerte de circuitos cerrados que ahora desconectamos. Desconectamos y, además, derivamos como se deriva una corriente. Derivamos la vida transcendental que en los acumuladores autoaperceptivos de la actitud natural se celaba. Derivamos la corriente de vida transcendental única y exclusivamente por el circuito de la concrescencia. Única y exclusivamente: sin darle ningún género de asistencia mediante los operadores de inclusión y pertenencia.

No bien desplegamos, desde el exclusivo circuito de la concrescencia, las partes concrescentes de la concreción fenomenológica, reparamos en que dichas partes no pueden compartir un mismo "espacio", por muchas que fueran las dimensiones de éste. Efectivamente, los asuntos-cosa, las Sachen, de la fenomenología, con parecer de una pieza, acreditan también un dibujo estructural complejísimo. Complejísimo no tanto por el detalle, la minuciosidad rizomática o fractal del arabesco que sus partes formarían, sino antes bien por contar, dichas concretudes, con varios relieves, relieves irreductiblemente distintos desde los que las partes hacen concrescencia. Más que complejidad (que también) hay -valdría mejor decir- dificultad. Dificultad y, sin embargo, aparente simplicidad. Apariencia que ya es un dato fenomenológico del que cumpliría dar cuenta. Apariencia que, como tal apariencia, no es falsa. Es, sencillamente, el modo de darse de la concrescencia. Incidamos, pues, en esa experiencia.

Efectivamente, esa complejidad estructural que, a grandes rasgos, hemos esbozado parece no avenirse con la relativa inmediatez (a pesar de su no localizabilidad) con que esas concretudes se sienten, dan noticia de sí. ¿Cómo es, vivida de cerca, efectivamente sentida, esta experiencia de inasibilidad de las "cosas mismas"? ¿Cómo se ofrece, en esa misma experiencia de inasibilidad, el haberlas casi asido o haber estado a punto de asirlas, es decir, la intuición en parpadeo (la "entreapercepción" diría Richir) de que éstas parecen ser algo, algo huidizo, ciertamente pero algo al cabo? Por lo tanto, ¿cómo, a pesar de todo, y a pesar de esa inasibilidad, presentimos que las cosas mismas de la 
fenomenología laten como (inconsútiles ${ }^{8}$ ) consistencias, como inasibilidades que, sin embargo, son algo-y-no-cualquier-cosa, algo sutil y, sin embargo, "de una sola pieza" ${ }^{\prime 9} \mathrm{o}$, si se quiere, algo que, en definitiva, es una concrescencia?

Las "cosas mismas" de la fenomenología son cosas que ya traban nuestro primer paso, cosas, quiérase o no, ya siempre "encabalgadas" ("enjambées" dice Richir) por cualquiera de nuestros movimientos (dada la compleja estructura antes mentada), cosas cercanas y esenciales que, con todo, ni esperan ni obedecen al apremio: prontas y lentas a un tiempo.

Hay aspectos de la concreción fenomenológica a los que podemos acceder, salvando las distancias, mediante lo que Ramón Gómez de la Serna decía sobre sus propias greguerías.

\section{EXCURSIÓN LITERARIO-GREGUERÍSTICA HACIA LA IDEA DE CONCRECIÓN FENOMENOLÓGICA}

No hay, evidentemente, un solapamiento estricto entre "concreción fenomenológica" y greguería. Diría que no toda "concreción fenomenológica" es greguerística, pero sí que toda greguería es, estructuralmente y, claro está, reducción transcendental mediante, del orden de una "concreción fenomenológica". Diría, sobre todo, que lo huidizo de la greguería se explica precisamente por el hecho de compartir ésta algo de la estructura general -incómoda, multiestratificada- de las "concretudes fenomenológicas". El modo huidizo y al tiempo enigmáticamente inconsútil de las greguerías -las hay, huyen pero ahí están, inasibles pero están- se debería, repetimos, a que éstas tienen esa misma estructura de concrescencia propia de las concretudes fenomenológicas, esa extraña inconsutilidad que articula cosas distintas, profundamente distintas

\footnotetext{
${ }^{8}$ Véase el uso profundo y fecundo que de este término hace Iván Galán Hompanera en su artículo "La fenomenología como atavismo", en el número especial de Arbor. Ciencia, Pensamiento y Cultura, vol. CLXXXV, 736 (2009), dedicado a la fenomenología, y coordinado por Agustín Serrano de Haro. Este artículo de Iván Galán Hompanera constituye, por lo demás, una concreta aproximación, desde un lenguaje distinto, no parafrástico, a algunos temas de la fenomenología de Marc Richir y de la fenomenología en general. Es un texto que puede leerse en paralelo a la primera parte del presente trabajo. Digamos que comparten un mismo propósito de fondo.

${ }^{9}$ Es el sentido primigenio de "inconsútil", referido a la túnica de Jesucristo. En el diccionario de la Real Academia leemos: "(Del lat. inconsutǐlis). adj. Dicho comúnmente de la túnica de Jesucristo: Sin costura". Túnica hecha de partes que, sin embargo, están ligadas entre sí pero sin precisar esas otras partes que fueran costuras, de modo análogo a cómo los momentos de un todo fenomenológico en sentido propio no necesitan partes suplementarias que aseguren la concrescencia entre los mismos. De no ser así, ello llevaría a un regreso al infinito, análogo al que entra en liza en el argumento del tercer hombre.
} 
(como son las varias partes de la concrescencia transcendental) presentándolas, sin embargo, como si fueran de una pieza.

Rescataremos, aquí y allá, en el cuerpo del texto y, sobre todo, en notas al pie (que ilustren fenomenológico-greguerísticamente los argumentos del cuerpo de texto, a veces inevitablemente abstractos) algunos pasajes del prólogo a Greguerías de 1960. Que, como las concretudes fenomenológicas, las greguerías tienen curso propio y no hacen acepción de apremios (que son, en general, ritmos "humanos demasiado humanos" ceñidos, las más veces, por el miedo), es cosa que nos dice Ramón Gómez de la Serna de varias maneras y en diversas ocasiones. Por ejemplo:

Me las concede esa adolescencia de la vida que es pareja de nuestra adolescencia o de nuestra vejez... Tienen que ser lentas y naturales. Son una gota de los siglos que atraviesa mi cráneo.

Y, más adelante, en ese mismo prólogo a Greguerías, este pasaje fenomenológicamente sobrecogedor:

La greguería no se encuentra a punto fijo o con seguridad en ninguna parte, pero de pronto se encuentra mirando esa escala de polvo que baja desde el sol hasta el suelo de la habitación y que se forma al dejar abierto sólo un intersticio de las contraventanas bajo el sol de las siestas de veraneo. iCon qué presentimiento de la greguería veíamos de niños esa espiritualidad material de la luz en la casa entornada de nuestra abuela!

Esencialmente renuentes $\mathrm{y}$, sin embargo, calladamente cercanas, casi indiferentes. Indiferentes a ser o no encontradas: estuvieron ahí siempre, no nos esperaban. Nuestro haberlas hallado tampoco las conmueve ni las modifica o desgasta: permanecen siempre frescas. Están bruñidas de una inmemorialidad -siempre estuvieron ahí- que es, al tiempo -diría Richir- inmadurez -siempre sin acabar de llegar del todo, siempre frescas, con una extraña impresión de recién encontradas que nunca caduca. Impera una soberana indiferencia de la greguería al sujeto que le sale al encuentro. Esa indiferencia es algo así como la cifra afectiva, inmediatamente sentida, de su transcendencia ${ }^{10}$.

\footnotetext{
${ }^{10}$ En consonancia con dicho carácter refractario a nuestra voluntad, o más bien soberanamente indiferente a la misma, nos dice Gómez de la Serna: "Se puede improvisar una novela pero no una greguería". Y, en ese mismo prólogo, algo más adelante: "La greguería es silvestre, encontradiza, inencontrable"; o también "La greguería es lo más casual del pensamiento, al que hay que conducir, para encontrarla, por caminos de serpiente, de hormiga o de carcoma, hasta ese punto de casualidad". (Como el resto de las citas de Gómez de la Serna de este trabajo, a no ser que explícitamente se diga algo en contrario proceden de: Ramón Gómez de la Serna, Prólogo a Greguerías, Madrid, Espasa-Calpe, 1960.)
} 
De un lado sentimos lo concreto de la cosa misma. De otro, nos resulta huidiza, como si estuviera más acá y más allá de nosotros mismos, como si sólo cupiera notar esa concretud en el parpadeo que va (y viene) del más allá del objeto al más acá del sujeto, como si el espesor propio de la concretud latiese en el quicio mismo que va del sujeto al objeto, quicio invisible y apenas henchido un instante, cuando sobre él se pasa. Ese quicio habremos de acercarlo, lento a lento, como quicio o articulación mereológica. Quede para otros trabajos cumplir con ese propósito. Digamos, por lo pronto, que no es quicio a ojos vista sino extraño quicio al que repugna todo en frente. Por él pasamos sin darnos cuenta, sin poder enfrentarlo o encaminarlo. Ausentes al preciso momento en que lo atravesamos, el guiño de la greguería siempre nos sorprenderá de soslayo. Las greguerías hacen concrescencia en los indisponibles parajes del soslayo. Mas todo esto, cuidado, no es porque ellas quieran. Expliquémonos, pues en esto se juega la recta comprensión de su transcendencia.

Las greguerías son huidizas por accidente. Que ese accidente sea permanente, que se produzca de continuo, que eso se viva siempre, es, a su vez, accidental, y accidental a su carácter de accidente. Así, las greguerías podrían no huir siempre o no resultarnos, siempre, huidizas: de nosotros dependería que así (no) fuera. Las greguerías son huidizas por accidente, y lo son por ser, en esencia, transcendentes y soberanamente indiferentes a nuestro afán de captarlas. Dicho de otro modo: las greguerías no son huidizas por haberse puesto a escapar de nuestro afán de caza. Nos son o resultan huidizas a nosotros, a nosotros que estamos, parafraseando un memorable poema de León Felipe, tan "cargados de tarjetas y de miedo". En otras palabras: si resulta que vamos al encuentro de la vida y las greguerías "cargados de tarjetas y de miedo" (el "sabio tímido" del impresionante poema Yo soy el gran blasfemo de León Felipe), eso es problema nuestro. Problema "humano demasiado humano" que a la greguería le trae sin cuidado. O, si resistimos (con términos más próximos a la fenomenología) a esa misteriosa tentación de animismo que cada greguería nos tiende, entonces diremos que esas cuitas nuestras y muy nuestras, tan infartadas de miedo como están, no pueden sino traer sin cuidado cuando se las contempla desde el situs arquitectónico de la greguería. Cuitas nuestras que, por ende, nos traen sin cuidado incluso a nosotros mismos si es que somos a hollar, siquiera en parpadeo, dicho situs, y, desde allí, a avistar nuestras preocupaciones enfundados, así fuera un instante, en la parte concrescente transcendental 
o constituyente que, celada en cada greguería, contiene ese ritmo y color de vida que nos franquea un acceso, acceso precisamente a esa greguería ${ }^{11}$. Las greguerías se limitan, en suma, a ser lo que son. Si resultan huidizas, lo son por accidente, y al crisol autoaperceptivo que juntos configuran esas "tarjetas" nuestras y el catalizador autoaperceptivo de nuestro "miedo". Ingredientes que tan maravillosamente bien capta León Felipe en el mencionado poema.

Al hiperbólico Ramón llega a desesperar (aunque, las más veces, sepa declinar esa desesperación en entretenimiento) la ilocalizabilidad de la greguería. Ilocalizabilidad que nada tiene de una suerte de complejidad cuántica que requiriese una afluencia de dimensiones y parámetros. Ilocalizabilidad que, más que compleja, es difícil ("clara y difícil" diría Bergamín). Ilocalizabilidad a sobrehaz de los mojones (auto)aperceptivos entre los que nos movemos. Estos mojones son lo que en la actitud natural entendemos por "sujeto", "objeto", "mundo", "vida" y, en suma, "afuera" y "adentro". Ilocalizabilidad de la greguería que le lleva a hacerse la hiperbólica pregunta siguiente: "¿Están fuera o están dentro?". A lo que Gómez de la Serna responde con la siguiente hipótesis (que sería largo comentar pero que, desde luego, no nos parece que abogue por una suerte de fenomenología de la inmanencia): "Yo creo que estamos compuestos de greguerías como de células, pero tenemos que poseer muy sutil oído para oírlas". Que quepa hacer esa disparatada pregunta y se aduzca el semejante disparate como respuesta, he ahí otras tantas llamadas de atención en punto a la necesidad de "mereologizar" las apercepciones que inervan la

\footnotetext{
${ }^{11}$ Las greguerías son cosa y afección. Pero afección suya. Exactamente igual a como sucede con el "objeto" -bífido- que late en el fondo de una metáfora lograda. Remitimos a los finos comentarios que Richir, en el primer capítulo, "Affection et Langage", de Sur le sublime et le soi. Variations II (Amiens, Mémoires des Annales de Phénoménologie, 2011), dedica a la extraordinaria parte sobre la metáfora del Ensayo de estética a manera de prólogo (1914) de José Ortega y Gasset. Cfr. José Ortega y Gasset, Ensayo de estética a manera de prólogo (1914), Obras Completas, Madrid, Taurus / Fundación José Ortega y Gasset / Centro de Estudios Orteguianos, 2004, vol. I, pp. 664-680.

No menos meritorio y extraordinario es el partido que Richir ha sabido sacarle a ese texto desde su lectura de la fenomenología de la phantasia y de la afectividad en Husserl, y desde el establecimiento o estabilización de su idea de la phantasia-afección. La primera estabilización clara de la "afecciónphantasia" la logra Richir en su artículo "Pour un phénoménologie des racines archaïques de l'affectivité", Annales de Phénoménologie 3 (2004) 155-200.

"Phantasia-afección" o "afección-phantasia" como a ella aconseja referirse Ricardo Sánchez Ortiz de Urbina. Quizá "afección-phantasia" trabe mejor la referencia a aquello a lo que Richir apunta cuando habla de las "phantasiai-affections", y es porque la afectividad es mucho más piedra de toque de la phantasia (de que nos hallamos de veras ante una phantasia y no ante una simple imaginación indeterminada) de lo que pueda serlo ésta de aquélla. Por eso estamos, en lo esencial, de acuerdo con la sugerencia que el propio Ortiz de Urbina le hizo, recientemente, a Richir.
} 
actitud natural, a disolver mereológicamente sus mojones. Lo hiperbólico es llevar hasta el final esta suerte de "reducción mereológica"12.

En punto a la hiperbolicidad ramoniana, no podemos por menos de citar el lúcido ensayo El disparate en la literatura española ${ }^{13}$, del (no menos hiperbólico) José Bergamín, otro de los grandes olvidados (junto a Ramón Gómez de la Serna) de la literatura (y del pensamiento) español del siglo XX. La última parte de este lúcido ensayo ${ }^{14}$ trata sobre el disparate (que, en cierto modo, es otra posible, muy española, figura de la hipérbole) en tres autores contemporáneos, a saber: Valle-Inclán, Unamuno y Gómez de la Serna. Bergamín, con el enorme talento y penetración que atesoraba, recoge las tres declinaciones que el "disparate (español)" conoce en cada uno de estos tres autores: el disparate como "esperpento" (Valle-Inclán), como "nivola" (Unamuno) y como "greguería" (Gómez de la Serna).

Citemos este desarrollo de José Bergamín sobre Gómez de la Serna, pasaje que guarda cierta relación con lo que el propio Ramón apunta sobre sus greguerías, con un componente de la experiencia de la greguería a que venimos apuntando: el de nuestra irremediable infidelidad ${ }^{15}$ a las mismas, el de nuestro pasar de largo, una y otra vez, in-advirtiéndolas como concretudes fenomenológicas, o advirtiéndolas demasiado tarde, arrojados como estamos a quehaceres humanos demasiado humanos o nuestros demasiados nuestros, acaso -quien sabe- quehaceres infieles a lo esencial. Esto nos dice José Bergamín ${ }^{16}$ sobre la declinación greguerística que el disparate conoce en Gómez de la Serna:

${ }^{12}$ Intento en "Concrétudes en concrescences", una caracterización de lo que llamo "reducción mereológica". La tesis fuerte estriba en que sólo la epojé hiperbólica puede cumplir hasta el final la "reducción mereológica". Ello se debe a la incidencia, en toda fenomenalización, de una concrescencia, de la parte fenomenologizante. Parte que, estando aparte, en parte también incide (incide como "parte") en la concrescencia de la vida transcendental y de sus concrescencias en general tal y como Husserl nos lo recuerda en varios textos de Hua XXXIV y no poco manuscritos del grupo B no editados, por desgracia, en Hua XXXIV. Pues bien, la epojé hiperbólica es el intento de tener también en cuenta esta incidencia del (a)parte fenomenologizante en las concrescencias.

${ }^{13}$ José Bergamín, El disparate en la literatura española, Sevilla, Editorial Renacimiento, 2005. Edición de Nigel Denis

${ }^{14}$ La que, en la citada edición, va de las pp. 82 a 99.

${ }^{15}$ Pero, ¿hasta qué punto irremediable? No sabemos, por hablar en los términos de Malidney, cuáles son los "límites" de nuestra transpasibilidad. No sabemos -por hablar con Spinoza- lo que un cuerpo puede.

${ }^{16}$ Veremos que este texto guarda íntima relación con un poema que, antes de editado y publicado, le manda Bergamín en una carta a María Zambrano. Cito ese poema en el último epígrafe de este texto, epígrafe dedicado a una primera comparecencia -e indiscernible parecencia- del Genio Maligno. Guardemos en mente, al leer ese sobrecogedor poema de Bergamín, lo que en estas líneas, y en un contexto, cierto eso, muy distinto, nos dice sobre el disparate en Ramón Gómez de la Serna. 
Lo profundo, en nosotros, es el disparate. Cuando ahondamos en nosotros mismos, encontramos siempre ese disparate frustrado de nuestro ser: el que debió haber sido nuestra vida o lo que debió haber sido nuestra vida y, por una razón o por otra -por razones tontas, por tontería o tonterías- hemos ido enterrando, invisiblemente, en nosotros, para siempre. Sentimos, entonces, en la vida, más que el remordimiento de los errores, de los pecados que cometimos, algo así como el remordimiento de los disparates que no hemos hecho. Toda la vida se nos llena de esta nostalgia. Y nuestra conducta nos parece el despojo de un disparate muerto. Toda la conducta de la vida se nos figura, entonces, ese resto mortal, esa huella disparatada de nuestro paso, como la de la camisa de una serpiente. ${ }^{17}$

"Despojo de un disparate muerto", "se nos figura", "resto mortal", "huella", "camisa de una serpiente". No son baladíes las resonancias que, en estas líneas de Bergamín, se dibujan en punto a la cuestión de la figuración, e incluso a la cuestión de la (insensata) posibilidad de una hiperbólica figuración -en clave de "Fiktum"18 - de la vida misma. Pero de la vida en su literalísimo sentido, es decir, de la vida en su calidad de reell ${ }^{19}$. Resonancias, decimos, que son como el eco anticipado (se verá) de lo que Husserl nos dirá en el inquietante $\S 114$ de Ideas $I$ y al que nos referiremos al final de este trabajo. Inquietantes ocurrencias del a veces hiperbólico Husserl que, como veremos, bien pudieran ser hipérboles bergaminescas (o unamunianas). Bergaminescas cosas (ipero en boca de Husserl!) en punto a la modificación de neutralidad, en punto a su vertiginosa, hiperbólica inercia de cuodlibetalidad -neutralizar cualquier(a)- y de ubicuidad -neutralizar doquiera.

\section{INMINENCIA, PARECENCIA Y MULTIESTRATIFICACIÓN DE LA EXPERIENCIA}

Evidentemente, hablar de una suerte de desenclave y suspensión de la vida en su calidad de reell se antoja un absurdo mayúsculo. Tamaña insensatez -acaso y sobre todo (aunque no sólo) ante Michel Henry- es la que la epojé hiperbólica richiriana preconiza. Insensatez que en su vertiente positiva ${ }^{20}$ persistirá cuando aduzcamos, con Ramón, que cada greguería nos endosa un

17 José Bergamín, El disparate en la literatura española, pp. 96s.

${ }^{18} \mathrm{Cfr}$. Hua XXIII, sobre todo el texto $\mathrm{n}^{0} 16$.

19 Temas que toca muy profundamente el artículo, de Marc Richir, "De la figuration en psycopathologie". Este artículo está aún inédito, pero es de inminente publicación. Una versión española de este texto aparecerá en el próximo número de Eikasia dedicado a Richir.

${ }_{20}$ Pues hay una vertiente negativa de la hipérbole, un modo negativo de prender y prender(me). Se trata de lo que Richir llama "sublime negativo", muy próximo a ciertos elementos de la congoja unamuniana. Cfr. Marc Richir, "Sublime et Pseudosublime", Annales de Phénoménologie 9 (2010). 
transcendental suyo que inhiere en nuestro transcendental propio hasta el punto de borrarlo (siquiera durante el instante de un parpadeo). He ahí el género de (trans)posibilidad (a inauditas concrescencias) a que abre el cogito hiperbólico, como si éste pretendiese habilitar más aún que la conciencia interna del tiempo (volvemos sobre el particular al final de este trabajo). Habilitar más aún pero, contrariamente a la cerrada continuidad de la conciencia interna del tiempo, al precio de habilitar en parpadeo, por eclipses sucesivos. El cogito hiperbólico es como la parte no suturada de los misteriosos hilvanes abiertos entre subitáneos descarrilamientos de la síntesis absolutamente pasiva de la llamada intencionalidad longitudinal. Trance de hilván, travesía en punto muerto, que fenomenaliza inauditas concrescencias al pairo de descarrilamientos que, claro está, no pueden ser completos y que, en los niveles arquitectónicos arcaicos en que ahora nos situamos, no corresponden a meras "desapariciones" o absolutas desconexiones, menos aún a simples no cumplimientos. Todo es, aquí, mucho más tenue e intrincado, mucho menos recortado, mucho menos cuestión, en punto a lo verdadero o a lo falso, del simple estar o no estar, darse o no darse, de entidades recortadas ${ }^{21}$. Hay, antes bien, una reconducción de la declinación ontológica de la cuestión de la verdad (o de la falsedad) a su genuina declinación fenomenológica, a la cuestión previa pero más sutil de la concrescencia (o de la alucinación de concrescencia), de la concreción (o de la pseudoconcreción).

Se trata de desajustes (nunca completos) entre las dos direcciones de la síntesis temporal: extraños hilvanes en las cerradas costuras de la intencionalidad longitudinal que, lejos de producir un desfondamiento de la propia síntesis transcendental, alientan en parpadeo rendimientos de inaudito alcance del lado de la intencionalidad longitudinal. Rendimientos que, por definición, no se sostienen, que dan lugar a "entreapercepciones" que sólo alcanzan a dibujarse (en orden a este doble desajuste; y para, al punto, borrarse) en ese especialísimo régimen de temporalización que es el de la phantasia en su diferencia con las

${ }^{21}$ Richir, gran lector y admirador de Antonio Machado, suele recordar en sus seminarios los tesoros metodológicos que, para el desarrollo de una fenomenología arquitectónica, encierra el Juan de Mairena. Richir ha insistido en ocasiones, ante su auditorio, en cómo Machado, en cierto modo, se percata de que, en los niveles de experiencia más recónditos, se ha de abandonar la cuestión de la unívoca presencia o de la ausencia, del ser (pleno) o de la nada (pura). Todo lo trastoca, claro está, la genial introducción machadiana de la "Otredad", la ínsita "heterogeneidad del Ser". Suele Richir referirse a las metafísicas apócrifas de Juan de Mairena y de su maestro Abel Martín, metafísicas en las que se sostiene que no hay creatio ex nihilo, que Dios, de crear algo, crea, todo lo más, la Nada, y "crea" el mundo no por un acto de creación sino -suele recordar Richir evocando a Machado- cubriéndose la mirada. 
temporalizaciones tanto de percepción como de imaginación. En esos hilvanes de descordinación entre síntesis longitudinal y transversal se abren concrescencias que se "gnotan", en primer término, a sobrehaz de ciertas modificaciones sitas en lo más profundo de la afectividad, última y fundamental piedra de toque -más allá de la phantasia o del esquematismo- de la fenomenología richiriana, pero donde a esa afectividad arcaica (relación de sí consigo inaudita en orden a un síntesis longitudinal parcialmente desfondada) responde algo protoontológico, algo del mundo de toda la vida que siempre estuvo y siempre estará y que entra en concrescencia con la afectividad en orden a una síntesis transversal inauditamente ampliada desde el "espacio" de ese hilván, desde ese doble fondo que se abre bajo el suelo aparentemente balizado de la síntesis longitudinal (declinando y desairando, por lo demás, la posibilidad de cerrar toda afectividad arcaica en auto-afección). No podremos tocar estas cuestiones, aquí, de lleno. Ahora bien, con vistas a las notas al pie con citas de Richir que se avecinan, quisiera dejar en depósito -dejar de entrada, cuanto antes dejar (por lo que pudiera pasar) - una clave hermenéutica que me parece fundamental y sin la que los textos de Richir, sencillamente, se cierran: se trata del concepto de inminencia, de su relación con los otros dos conceptos mentados en el epígrafe que encabeza estas líneas.

Dicho rápidamente, so pena de que nos embalsemos por completo en este meandro: cuando, dada la multiestratificación de la experiencia ${ }^{22}$, nos las habemos con fenomenalizaciones que se juegan en niveles muy arcaicos, sucede entonces que esas fenomenalizaciones, con ser (a pesar de todo) algo (y no pura nada, no palabras y nada más que palabras, blosse Meinungen), no se cumplen del todo. Son "sentidos" que, sin ser equiparables a meras significaciones, no se pueden ejecutar hasta el final. Nos referimos a fenómenos inejecutables hasta el fondo, incompletos, como esa encarnadura del ebrio de poema en la parte-"vida" inherente a una greguería (parte-"vida" como parte suya, como parte concrescente de la greguería). O a fenómenos invivibles hasta el fondo pero que gravitan como inminencias cual la comparecencia (que no es presencia) del Genio Maligno en el trance de duda hiperbólica que atraviesa

\footnotetext{
${ }^{22}$ Concepto richiriano que Ricardo Urbina ha captado con enorme profundidad. La multiestratificación de la experiencia es el "dato" fenomenológico fundamental que motiva la elaboración de una fenomenología bajo la forma de una arquitectónica fenomenológica. Cfr. Ricardo Sánchez Ortiz de Urbina: "Introducción a la estromatología", Eikasia 40 (2011) 147-182.
} 
Descartes. Trance a que con tantísimo tino se refiere García Lorca en su memorable conferencia Juego y teoría del Duende $e^{23}$.

Aludimos a fenómenos como los que, en ocasiones, relatan Unamuno o Bergamín. Fenómenos de puesta en solfa de ciertas continuidades cerradas (como la del tiempo inmanente). Puestas en solfa que, repetimos (para no ser malentendidos) corresponden, en esos niveles arquitectónicos, no tanto a la simple decepción de una Erfüllung que dejara de darse, cuanto a una Fühlung inaudita. "Puestas en solfa" que se sienten por dentro, por "tacto interno" como diría Maine de Biran, bajo la forma de modulaciones afectivas ${ }^{24}$ absolutamente inauditas y desconocidas, que no fundan ni pueden fundar hábito, y donde, por caso, parece como si estuviéramos en inminencia de pasar del otro lado de la síntesis de la intencionalidad longitudinal. Me refiero, por caso, a los fenómenos tan unamunianos y bergaminescos de sentirse uno, de repente, fantasma por dentro. Fenómenos nunca cumplidos que se ofrecen siempre bajo la especie (¿acaso también en el sentido de la synthesis speciosa de que nos habla Kant?) de inminencias que, a veces (caso del "sublime negativo") amenazan cumplimento, cumplimiento que entrañaría nuestro absoluto desleimiento. Son fenómenos típicamente unamunianos y bergaminescos que repugnan a la Verdad inconcusa de la Vida proclamada, por ejemplo, por la fenomenología de Hen$r y^{25}$, o por las filosofías de Bergson o de Deleuze.

Llegar al extremo de dudar de mi propia adscripción al carácter reell, a la "Reellität" de mi vida, llegar a la insensatez de ver incluso lo reell de mi vida como iun fenómeno más!, todo eso, todas esas insensateces, son inminencias, fenomenologías encetadas pero incumplidas. Son inminencias a las que sólo cabe habilitar un entero derecho fenomenológico merced al atento despliegue del abanico arquitectónico que da cuenta del hecho, las más veces obliterado, aplastado, de la multiestratificación de la experiencia. De ahí que estas inminencias estén, las más veces, aplastadas por la Verdad del Mundo; aplastadas

${ }^{23}$ Federico García Lorca, Juego y teoría del duende, en Obra completa, vol.VI: Prosa, 1, Madrid, Akal, 2008.

${ }^{24}$ Suerte de recóndita base fenomenológica de las modificaciones y de las modalizaciones dóxicas. La fenomenología de la afectividad es la base última de toda arquitectónica fenomenológica y, por ende, de la fenomenología de Richir.

${ }^{25}$ Verdad proclamada, por otro lado, con enorme profundidad. Contra lo que pudiera parecer, no hay un ápice de ironía en estas líneas. La empresa fenomenológica de Henry es original y respetable. Inaudita, para mí, en el panorama francés de la fenomenología contemporánea, tan muñido de falsas originalidades 0 , lo que es aún peor y mucho más triste, de originalidades alucinadas (de puro apetecidas). En ese mar de vanidad despunta -más acá de toda verdad o falsedad- la honestidad filosófica de un Michel Henry. 
también ("écrasées") por la masiva fenomenalidad autoafectiva -sin resquicios- de la Vida (la autoafección henryana como "phénomène écrasé", la vida invisible, nocturna, sin distancia en su "phénoménalité écrasée").

Entre los macizos supuestamente inconcusos y concluyentes de vida y mundo prenden, por veces, filigranas de inminencia que parecieran moverse a otro ritmo y hacerlo como en otros estratos. Mas son estratos que, con todo, no nos son del todo ajenos y a los que somos, en parte, "transpasibles". Esas inminencias tienen su derecho fenomenológico. La dificultad estriba en describirlas en sus términos; y eso requiere, naturalmente, la determinación y desbroce de su situs arquitectónico. Es lo que permite ser justo con esos fenómenos, no asemejarlos, de entrada, a meras quimeras.

En otras palabras: no todo lo que, por caso, parece, visto desde el estrato arquitectónico de la actitud natural (o del presente unívocamente asignable), como mera quimera nos aparecerá luego, una vez desplegada la multiestratificación de la experiencia, como tal quimera (lo que no quiere decir que sea una "entidad") o, siquiera, como quimera del mismo orden (que otra cualquiera). No todas las no nadas son nonada, ni las nonadas nonadas del mismo orden. Dichas inminencias tienen su derecho, su carta fenomenológica de naturaleza porque no son cualquiera. Lo tienen allí donde hay "cosas", Sachen, que no hallan unívoco cumplimiento; que no lo hallan no por ser puro aire, sino porque, sencillamente, no son ni entidades recortadas (claras y distintas) ni tampoco presencias masivas (del orden de la claridad no distinta del cogito tal y como aparece en determinados niveles arquitectónicos).

No es cierto que, en punto a estas inminencias "valga lo mismo 8 que 80". ¿En qué y por qué? Concederles carta de naturaleza fenomenológica -a expensas de la determinación de un situs o residencia arquitectónica- no quiere decir concederles, ipso facto, patente de corso: media, precisamente, el quehacer arquitectónico. No todos los Ansätze ${ }^{26}$ que desde la modificación de neutralidad puedan hacerse prenden de idéntica manera en la concrescencia de una phantasia-afección o de una -por hablar como Urbina- afección-phantasia. Dicho de otro modo: entre las meras menciones intencionales (hipotéticas) y los diversos modos de plenificación unívocos y objetuales hay, en los niveles fenomenológicos más arcaicos, lo que, en una nota posterior, llamo, con una antigua palabra

${ }^{26}$ Cfr. Hua XXIII, texto no15. 
del español, "parecencias"27. Son hipótesis que, fenomenológicamente, prenden, que hallan, en lo más recóndito de los abismos de vida y de mundo, réplica (de afección-phantasia). Mas prenden como inminencias de fenomenalización nunca cumplidas del todo, irreductiblemente insaturadas. ¿Prenden? ¿Réplica? ¿No será que ilusionamos esa réplica? ¿Qué distingue a esos íncipit del pensamiento, a esas inercias incumplibles (por invivibles) de meras ilusiones? ¿No será que, cerrando un inadvertido pacto con el diablo, empujamos con la mano izquierda las quimeras que, como si de nada fuera, recoge la mano derecha bajo la especie ("speciosa" especie) de presuntas concrescencias? ¿No será que el Genio Maligno infunde en nosotros la synthesis speciosa de ignotas pseudo-concrescencias, ilusiones entusiasmadas, entusiasmos ilusorios, alucinaciones de pertinencia condenadas, el día más pensado, a virar hacia un profundo desencanto? Mas, sobre todo, ¿cómo seríamos a notarlo ${ }^{28}$ ? Formulado de otro modo: uno de los abismos de la parecencia reside en la cuasiindiscernabilidad entre la concreta experiencia de una inminencia y la mera inminencia de una experiencia. Unamuno de un lado, Machado de otro, han tocado este punto con una enorme profundidad. De ahí el sostenido interés que Richir manifiesta por la obra de ambos.

\footnotetext{
${ }^{27}$ Ricardo S. Ortiz de Urbina ha rescatado, en el contexto de su "materialismo fenomenológico", la palabra "aparencia". Se trata, grosso modo (pues la cosa es mucho más compleja) del correspondiente fenomenológico del primer género de materialidad (M1) en la filosofía de Gustavo Bueno, sólo que desplazado, en su estromatología, a lo que Urbina llama "nivel 2" o nivel de los sentidos in fieri (si caracterizamos el nivel 2 mediante el aspecto que a su paso por él toma la vertical del sentido o del significado; hay, naturalmente, muchas otras verticales y caracterizaciones posibles del nivel 2, y, por ende, de cada uno de los otros cuatro niveles horizontales que configuran la "estromatología" de Urbina, la matriz arquitectónica de su materialismo fenomenológico).

${ }^{28}$ Hay elementos de respuesta a esta cuestión que no desplegaré en estas páginas sino en la mencionada segunda parte de este artículo. En realidad, concrescencia y pseudo-"concrescencia" se sitúan en niveles arquitectónicos ligeramente distintos (por eso no es exacto decir que hay algo así como un prôton pseudos). La pseudo-"concrescencia" se ve asistida por lo que Fink denominaba "mundanización impropia", concepto del que, como se ve, haremos un uso algo distinto que, sin embargo, pretende ser fiel a su sentido. Evidentemente, esto sólo en posible a través de un análisis mereológico fino de la "mundanización impropia". Ése es, al menos, nuestro propósito, y el que entendemos, por ahora, como nuestro camino. Visto lo mismo del lado de la teoría transcendental de los elementos, la pseudoconcrescencia requiere al menos dos veces del fenomenologizar. La concrescencia, en cambio, se fenomenaliza en una sola rasada fenomenologizante. Todo esto puede tener, creo, su beneficiosa aproximación mereológica. Aproximación ayudada por el hecho, esencial aquí, de que phantasia e imaginación (o, como diría Richir, "phantasia-afección" e "imaginación-afecto") tienen estructuras aperceptivas distintas. El problema estriba, claro está, en su discernimiento, y más específicamente en no tomar por una phantasia lo que, en realidad, es una imaginación, por indeterminada que sea. La piedra de toque está en la estructura aperceptiva puesta en juego (directa en el caso de la phantasia, bífida en el caso de la imaginación) y en la relación mereológica de la parte concrescente afectiva que se da en cada uno de los dos casos. Así, por ejemplo, "imaginación" y "afecto" tienen a escindirse, a ser concretos en inminencia de ser (relativamente) independientes, cosa que no ocurre con la phantasia y su afección cuya profundidad fenomenológica estriba, precisamente, en ser momentos el uno del otro dentro de un todo en concrescencia. Ese ejercicio de discernimiento es, precisamente, arquitectónico, es, en parte, hacer arquitectónica fenomenológica, saber en qué situs arquitectónico residenciar tales o cuales concretudes fenomenológicas.
} 
En ese proceloso terreno se mueve la fenomenología de Richir y se trata de no cerrarse, de entrada, a todo ello. Al fin y al cabo, también en estos parajes sigue valiendo, como no podría ser de otra forma (si es fenomenología lo que se está haciendo), el principio de todos los principios enunciado por Husserl en Ideas I. Ocurre, sencillamente, que en los niveles más arcaicos de la experiencia, las concretudes fenomenológicas lindan con sus ilusiones transcendentales. ¿Cómo arreglárselas? Pues bien, no será de la mano de una Erfüllung en el sentido clásico, de la donación de un fenómeno saturado (en el sentido de Marion) o del de suyo de la impresión de realidad (en la versión seria, honesta y verdaderamente profunda que la fenomenología de la donación de Marion conoció, por anticipado, en las elaboraciones, muy superiores, de Xavier Zubiri). Se trata, más bien de una Fühlung. En cualquier caso, y por no detener más el curso del texto en este meandro tan lleno de prevenciones, el paso de ente, ser o donación, a concrescencia entiende poder trabajar en este proceloso ámbito en que las concretudes están nimbadas de ilusión transcendental.

Obviamente, la piedra de toque última de la concretud y de la fenomenología de Richir es la afectividad (lo cual no quiere decir que tampoco ella esté a salvo de engaño). En cualquier caso, valgan estas líneas para, acaso teniendo muy presente el abanico de profunda no univocidad (arquitectónica) de la (no) donación del fenómeno que abre el hecho de la multiestratificación de la experiencia, no desestimar de entrada por absurdas (como si de argumentos se tratara) ciertas inminencias concretas (pero concretas precisamente como inminencias). No son registros donde quepa dar con algo mediante algo así como un "argumento"; lo cual no quiere decir (éste es el punto) que impere aquí la más absoluta de las irracionalidades. No. Hay arquitectónica. Hay, al menos, el intento de su establecimiento. En ella situamos esas inminencias concretas que lo son de actos no efectuables hasta el fondo. Actos como, por ejemplo, el cogito hiperbólico, o la epojé hiperbólica misma. Inminencias que, claro está, tomadas en otros términos, en los términos de un estrato arquitectónico impropio, se vuelven humo puro, palabras parangonables con el más vacío de los disparates. Marrar la fenomenalidad de esas inminencias es, de entrada, oponerles argumentos como, por ejemplo, el de la inaceptabilidad fenomenológica de un prôton pseudos, o, mejor dicho, introducir la cuestión fenomenológica del prôton pseudos como argumento. 
$Y$ es que todo se complica si se tiene presente la multiestratificación de la experiencia. $Y$ todo está en comprender que dicha multiestratificación despliega en niveles el modo en que las observancias de la "noética pura" husserliana se imponen pues no somos, en todos y cada uno de esos niveles, idéntico tipo de conciencia ${ }^{29}$. Ocurre, antes bien, que lo "verdadero" se ha complejificado estromatológicamente y que cada estrato tiene una determinada sintonía mereológica $^{30}$, un determinado ritmo de concrescencia al que hay que hacer justicia y que, en suma, no hay que aplastar sino desplegar manteniéndose atento a los más ínfimos matices. Dicho lo cual podemos, cerrando este paréntesis, volver al curso principal de nuestro texto.

Lo que José Bergamín ve perfectamente en Ramón Gómez de la Serna, es la originaria multiplicidad de ese disparate, ya ínsita en el propio término: disparate. Por definición no puede haber un solo disparate. "Disparate" dicho en singular es un mero nombre genérico. El disparate concreto es siempre vario, es uno de tantos (otros posibles y en su mayoría inopinados, ni siquiera sospechados). Así, lo disparatado -a que faltamos- es, de entrada, disparate vario. Eso que se nos escapa, eso a lo que no sabemos ser fieles parece, por cerca que esté, como ir a otro ritmo. Pero, ¿cómo de otro?, ¿y cómo es que lo sé? ¿Cómo es que lo noto? ¿Por qué no me detuve, entonces, a notarlo a pie fijo? Pues, ¿podemos, de veras, asegurar que no pudimos? ¿Dónde fue no poder y dónde no habernos atrevido? Y es que eso, tan múltiple y silvestre que ni siquiera se compadece con (factor de transcendencia de la greguería) ni se compadece de (factor de indiferencia) el tiempo de una vida ${ }^{31}$ y menos aún con/de el deber de unidad hermenéutica a que nos impetra nuestra propia la muerte. De ahí que estemos aquí a años luz de la autenticidad heideggeriana. A años luz desde una profundidad fenomenológica que es profundidad estromatológica (por retomar el término de Urbina), profundidad de una consonancia de vida con mundo que no espera, que siempre fue (lo que Richir entiende como la in-

${ }^{29}$ Cfr. Marc Richir, "Analítica arquitectónica de la génesis fenomenológico-transcendental del sí mismo (escorzo)", Eikasia 34 (2010) 459-471.

${ }^{30}$ He desarrollado esos conceptos en el siguiente texto: Pablo Posada Varela, "Fenómeno, concepto, concreción: el quehacer fenomenológico richiriano (A modo de introducción a 'Schwingung y fenomenalización' de Marc Richir)".pdf, Eikasia 40 (2011) 449-482.

31 "Tous ces termes sont l'indication, nominalisante dans la langue de la philosophie, de problèmes 'à résoudre', et qui, en un sens, ne seront jamais 'résolus', parce que, en un autre sens, leur 'résolution' demande du temps, et du temps selon plusieurs rythmes à la fois, dont certains, excessivement rapides, passent le plus souvent inaperçus, et dont d'autres, excessivement lents, demanderaient sans doute une durée de vie excédant largement la durée de la vie humaine". Marc Richir, Méditations Phénoménologiques, Grenoble, J. Millon, 1992. p. 379. 
memorialidad de un pasado proto-ontológico) y siempre será (lo que Richir entiende como la inmadurez de un futuro proto-ontológico) y que, desde luego, ni nos contempla (tanto en el sentido de vernos como en el sentido de no tener, de "no andarse con" contemplaciones) ni, menos aún, mira por nuestra muerte y por los gradientes de totalización y repliegue biográfico que ésta nos impone mediante ese catalizador autoaperceptivo que es el miedo.

No hay, al albur del encuentro con la greguería, esencialidad propia y menos aún esencialidad una. La greguería es ese albur. Puro albur. Refresca y aligera. Nos permite descansar de nosotros mismos. La muerte, fuera de juego, no es ya piedra de toque de ningún sentido, de ningún proyecto de sentido azuzado por su anticipación y obligado a ser uno. Lo que hay, de entrada, son esencialidades irreductiblemente múltiples ${ }^{32}$ : multiplicidad en plétora de esencias salvajes, la plétora de esencias salvajes a que se refiere Richir, fiel, en esto, a Merleau-Ponty.

Estas esencias salvajes tienen la particularidad estructural de ser esencias transcendentales ("rayos de mundo" dice el Merleau-Ponty de las notas de trabajo de Le visible et l'invisible). Esencias pero en sentido propio, es decir: esencias esenciantes (Lévinas habla, a veces, de "essance" ${ }^{\prime 33}$ ). ¿Qué se quiere decir con ello? Pues que, en esto, tanto Richir como Merleau-Ponty ( $y$ antes Fink en el abismal $\S 9$ de la VIa Meditación cartesiana) son enteramente consecuentes con el giro transcendental de la fenomenología. Quiere decirse, nada más y nada menos, que esos "objetos" que son las esencias salvajes (o las greguerías) albergan la complejidad estructural (mentada al principio de este

32 "Fécondité étrange de la phénoménologie, dira-t-on. Étrange, sans doute, parce que abyssale, parce que le père fondateur, Husserl, est sans doute le premier qui découvrit, peut-être à son corps défendant, ce qu'était une véritable multiplicité, en termes cantoriens, une multiplicité 'inconsistance', intraitable par l'ontologie encore sous-jacente aux mathématiques". Marc Richir, L'Expérience du penser, Grenoble, J. Millon, 1996, p. 470.

${ }_{33}$ Debo a Thomas Maurice el haberme llamado la atención sobre este interesantísimo punto. Así, Lévinas, en la nota preliminar de Autrement qu'être. Au-delà de l'essence considera la posibilidad de usar o haber usado el término "essance": «La note dominante nécessaire à l'entente de ce discours et de son titre même doit être soulignée au seuil de ce livre, bien qu'elle soit souvent répétée au cœur de l'ouvrage : le terme essence y exprime l'être différent de l'étant, le Sein allemand distinct du Seiendes, l'esse latin distinct de l'ens scholastique. On n'a pas osé Icrire essance comme l'exigerait l'histoire de la langue où le suffixe ance, provenant de antia ou de entia, à des noms abstraits d'action. On évietra soigneusement d'user du terme d'essence et de ses dérivés dans leur emploi traditionnel. Pour essence, essentiel, essentiellement, on dira eidos, eidétique, éidétiquement ou nature, quiddité, fondamental, etc.».

Podrá consultarse, también sobre este punto, la extraordinaria contribución de Thomas Maurice al próximo número especial de Eikasia www.revistadefilosofia.com dedicado a Marc Richir. Efectivamente, a lo largo de su Mon(a)de. Esquisse d'une topologie transcendentale, Thomas Maurice realiza, de hecho, otra propuesta terminológica que, a mi modo de ver, resulta más brillante y afortunada que la del propio Lévinas : se trata del término "escence" (que podríamos traducir en castellano por "escencia"), auténtico hallazgo terminológico a cargo de este prometedor filósofo y fenomenólogo. 
trabajo) de incluir cada vez una parte concrescente transcendental. He aquí, una vez más, la intrincación estructural de las cosas mismas de la fenomenología, de los fenómenos fenomenológicos. Quiere decirse que son miríada de transcendentales (concrescentes) irreductiblemente varios, distintos y suyos. Son "jeseinig", neologismo alemán que Richir opone a la Jemeinigkeit heideggeriana. Jeseinigkeiten de un transcendental (el que, querámoslo o no, la greguería, ya siempre nos ha endosado desde el momento en que la comprendemos) que es suyo: el propio y apropiado a/para cada greguería, como si cada una de ellas impusiera desde sí su timia transcendental, como si cada una llevara o incluso fuera no sólo "objeto" (e incluso "recóndito objeto"), sino también la concrescente timia transcendental que da acceso a sí misma. Arcana timia a la que, como sujetos in-definidos entre finitud e infinitud, nos descubrimos "transpasibles"34. La greguería no es objeto sino concrescencia. Por eso es, ya desde el punto de vista estructural, una Sache fenomenológica. Concrescencia de horizontes de mundo, vida y tiempo que acaso no sean los nuestros.

La epojé hiperbólica richiriana es el esfuerzo de descoincidencia con uno mismo que abre in-definidamente esa transpasibilidad, y que, para hacerlo, llega al extremo de convocar al mismísimo Genio Maligno. Meramente convocarlo desenclava afectivamente lo reell de la vida, trastoca la cerrada dirección de la síntesis longitudinal de tal forma que eso permite concrescencias inauditas. Eso rinde la epojé hiperbólica ${ }^{35}$. Hacerse a esas partes concrescentes que cada greguería nos endosa es precisamente lo que Richir entiende por "modificación en phantasia", donde esa phantasia poco tiene de las imágenes que nuestra imaginación puede montarse, y en las que alcanza aún, mal que bien, a reconocerse cuando no a engañarse ${ }^{36}$.

34 El concepto es de Henri Maldiney. Cfr. Henri Maldiney, "De la transpassibilité", en Penser I'homme et la folie, Grenoble, J. Millon, 1991.

35 La epojé hiperbólica requiere, repetimos, siquiera la parecencia de algo así como un Genio Maligno, o requiere, al menos, que esa parecencia (1) no se tome como mero contrasentido -en cuyo caso abandonamos la filosofía y la fenomenología, no le hacemos justicia a lo más profundo de lo humano, es decir, a la crítica y esencial no adherencia de la experiencia consigo misma-, (2) pero tampoco, de la mano de la superstición, se convierta en firme creencia (Cfr. Bergamín) o, caso de la psicosis, en alucinación de evidencia (sobre todo en ese tipo de psicosis que es la esquizofrenia).

${ }^{36}$ Puede que a la luz de la genial distinción husserliana entre Phantasia e Imaginación (dos tipos de acto con estructura aperceptiva distinta, como se verá en el texto de Richir sobre el particular publicado en este mismo número de Investigaciones fenomenológicas) y al amparo del contexto de la temática que nos ocupa, cobren estas otras líneas del Prólogo a Greguerías de Gómez de la Serna una nueva, insospechada profundidad: "Nunca pueden ser rebuscadas. Hay que esperarlas deambulando o sentados. $\mathrm{Ni}$ un paso voluntario hacia la imagen". 
Excuso decir -cumple insistir en ello- dónde queda, expuestos al arcaísmo de las greguerías y de las esencias salvajes, la unidad de la Eigentlichkeit heideggeriana. Donde queda, incluso, la muerte (que no la finitud). La muerte propia. Ésta queda, precisamente, puesta entre paréntesis. Al albur de las greguerías nuestra Jemeinigkeit se pone entre paréntesis para dar paso, como nos dice Richir, a una Jeseinigkeit, Jeseinigkeit de los sentidos por hacer, Jeseinigkeit múltiple ${ }^{37}$ y que, precisamente por ser otro su ritmo, nos refresca, nos saca de nosotros, nos "desobceca" como dice Ramón en punto a las greguerías:

La greguería desobceca, la greguería es matar a su tía, la greguería es el nombre más apropiado de las cosas, la greguería es revolución serena y optimista del pensamiento. ${ }^{38}$

Que la greguería nos toque, que nos sobrecoja tan profundísimamente, tiene que ver con el hecho de que comparta la estructura (mereológica) de la concreción fenomenológica, a saber, con el hecho de traer consigo la constricción de timia a que nos somete, el transcendental suyo con el que domeña y somete cualquier transcendental nuestro, cualquier obcecación de Eigentlichkeit en consonancia con la muerte propia. La greguería se mofa de nuestra propia muerte y nos pone a algo muy recóndito pero no por ello menos particular, menos despojado de una particularísima quididad. Nos pone, de espaldas a nuestra propia muerte, a vivirla a ella: esa greguería, engreguerizándonos a expensas de muerte (y proyecto propio) y al albur de esa (y no otra) greguería. Ese no mirar siquiera por nuestro proyecto propio, recortado bajo el fondo de la

37 Por no trabar el curso principal del texto con citas difíciles y demasiado largas que nos llevaría mucho tiempo poder explicitar (puede uno, empero, referirse a otros artículos en español ya publicados en Eikasia), nos permitimos citar en nota al pie, in extenso, otro pasaje más de las Méditations phénoménologiques, de Richir que, creo, puede leerse en íntima resonancia con lo que estamos apuntando:

"C'est dire [...] que toute centration des phénomènes dans une 'sphère d'appartenance' (Husserl, mais aussi Heidegger) est illusoire -en un sens l'illusion transcendantale du simulacre ontologique- ou c'est dire, en d'autres termes, que l'auto-aperception concrète du soi incarné, du soi phénoménal dans sa facticité, est irréductiblement décentrée, en porte-à-faux indéfini par rapport à elle-même, originairement distordue par non-coïncidence réciproque de son dedans et de son dehors, et donc qu'il y a en quelque sorte, 'en son' phénomène, 'autant' de paraître lui 'appartenir' que de paraître ne pas lui 'appartenir' en propre, 'autant' de Jemeinigkeit que d'anonymat phénoménologique -et c'est ce qui rend définitivement impropre l'expression heideggerienne de 'possibilité propre- ou de 'possibilité la plus propre', qui relève seulement du champ des déterminités symboliques.

Cela signifie que je ne viens $\mathrm{m}^{\prime}$ incarner concrètement dans mon auto-aperception que comme champ de possibilités ontologiques d'exister qui ne sont telles que de s'inscrire, toujours déjà et pour toujours, dans le champ plus vaste de transpossibilités indéfinies de facticités. Cela signifie aussi, corrélativement, que le monde, dans l'illusion transcendantale de sa Jemeinigkeit exclusive, n'est en réalité, nous l'avons déjà indiqué à maintes reprises, que l'implosion ou la condensation, par centration impropre et exclusive, d'une pluralité phénoménologique originaire de mondes; et tout aussi corrélativement, qu'il n'y a pas, en réalité, d'autres phénomènes que des phénomènes de monde". Marc Richir, Méditations phénoménologiques, pp. 121s.

38 O también: "La greguería resuelve las hinchazones con que todo se hinchaba". 
anticipación de nuestra propia muerte es, precisamente, lo que nos resarce, lo que nos refresca cuando contraemos - casi podríamos decir- una determinada greguería, cuando nos sorprendemos contagiados por ella:

La greguería resarce, consuela, es un refrigerio inesperado. Sacia como un cuscurro de pan entre planes y planes, o como un vaso de agua entre la sed falsa de los negocios o de las especulaciones incurables.

Esas inercias transcendentales suyas a que nos impetran las greguerías, esa suerte de curvaturas inducidas en "nuestro" transcendental no bien nos acercamos a la "singularidad absoluta" que es cada una de ellas, esos "disparaderos" -digamos en homenaje a Bergamín- múltiples, que son toboganes de vida nueva pero no cualquiera, eso precisamente es lo que Ramón Gómez de la Serna mienta, esta vez en el Prólogo a las Novelas de Nebulosa ${ }^{39}$, como las "ortopedias del vivir":

El que sea una novela de la nebulosa no quiere decir que tenga nebulosidades ${ }^{40}$, pues he intentado entrar en las sombras de la antemuerte y descubrir no por prurito de novedad ni de originalidad cosas ortopédicas del vivir.

Eso que nimba nuestro quehacer y que nuestro quehacer, quiéralo o no, ya siempre está atravesando, son las concretudes fenomenológicas, las concretudes fenomenológicas de que nuestra vida transcendental está tejida, y que han de pensarse a sobrehaz de vida transcendental; vida que las más veces está, obviamente, obliterada por la actitud natural: obliterada como transcendental y como vida. Esas concretudes (las cosas mismas a que la fenomenología ha de ir) se sienten, decíamos, cuando pasamos por ellas, cuando, de un modo otro y mal que bien, somos de ellas 0 , hasta cierto punto, nos hacemos a ellas. Pasamos en irremediable desajuste, desacordados. Notamos que por ellas pasamos porque nos cambian el paso. Aunque no del todo; sólo lo suficiente como para notar que encabalgamos algo más que nuestro propio paso, paso propio que, de otro modo, ni siquiera notaríamos cambiado, trastabillado.

\footnotetext{
${ }^{39}$ Ramón Gómez de la Serna, en el prólogo al grupo de novelas conocido como "novelas de nebulosa". Este prólogo fue publicado en 1946 al frente de El hombre perdido, Madrid, Espasa-Calpe, 1962, pp. 7-17. La denominación "novelas de nebulosa" también agrupa, al parecer del propio Gómez de la Serna, otras novelas como El incongruente (de 1922) o El novelista (de 1923).

${ }^{40}$ Las greguerías son "oscuras y distintas" si retomamos aquí el uso fecundísimo que Ricardo S. Ortiz de Urbina hace de la clasificación de Baumgarten. Cfr. Ricardo Sánchez Ortiz de Urbina, "L'obscurité de l'expérience esthétique", en Annales de Phénoménologie 10 (2011). Cuando Bergamín habla de "claro y difícil", que así titula una recopilación de textos, se refiere, en el fondo, a lo mismo, al mismo nivel de experiencia. La contradicción es sólo aparente.
} 
De esto último habremos de sacar, enseguida, importantes consecuencias. Y lo haremos no ya, como hasta ahora, situándonos del lado de la teoría transcendental de los elementos, sino del lado de la teoría transcendental del método (lo cual será motivo para aclarar el sentido de ambas nomenclaturas).

\section{DEL LADO DE LA TEORÍA TRANSCENDENTAL DEL MÉTODO:}

EL DESAJUSTE NO ESQUEMÁTICO COMO MATRIZ DE LA TEORÍA TRANSCENDENTAL DEL MÉTODO

Efectivamente, sin ese desajuste recíproco entre nosotros mismos y las concretudes no las gnotaríamos ${ }^{41}$ siquiera. Permanecerían ignotas si nos hiciéramos de inmediato a ellas. $\mathrm{Y}$ a nuestro paso (siempre demasiado rápido $\mathrm{y} / \mathrm{o}$ demasiado lento) punzan como un nervio de nuestra Leiblichkeit; algo de la "agilidad del pensar" (la expresión es de Fichte ${ }^{42}$ ) se ve sutilísimamente trabado o contrarrestado, y en ese desajuste se revelan como concretudes, revelando, al tiempo, ese desajuste mismo. Desajuste que es el hecho inconcuso de nuestra no coincidencia con las cosas de la experiencia, e incluso con la propia experiencia, desajuste que es cifra tanto de nuestra incardinación simbólica (y no sólo fenomenológica) como de nuestra inalienable libertad.

Libertad incluso respecto de lo fenomenológico. Richir insiste, por caso, en que lo propio de lo humano reside en una fundamental no adherencia (evidentemente no siempre actualizada) respecto de la experiencia. Se trata, por lo tanto, de una libertad que no siempre está empuñada en los niveles más arcaicos de la experiencia. Ahora bien, incluso en esos niveles hay virtual descoincidencia, desajuste ("écart"). Si bien no hay libertad en primera persona, sí hay matriz de libertad (fenomenológicamente atestada como matriz en la experiencia de lo sublime), y la hay -repetimos- no sólo respecto de las particiones

${ }^{41}$ Neologismo de Zubiri que nos parece interesante recuperar aquí. Zubiri habla a veces de las notas de la talidad como lo gnoto.

${ }^{42}$ La recoge y comenta Richir en un largo artículo (titulado "Hyperbole et Malin Génie"), artículo aún inédito, y de próxima publicación. Presumiblemente en el próximo número de Annales de Phénoménologie. Por lo demás, y en relación a la temática que enceta este párrafo, remitimos por anticipado, de un lado, a la imponente parte dedicada a la interpretación richiriana de Fichte que Sacha Carlson ha incluido en su tesis. De otro, a las investigaciones en curso de Iván Galán Hompanera sobre la profundísima (mucho más de lo que suele pensarse) asimilación que hace Husserl de Fichte, y que se verán en parte atestadas por el volumen de husserliana, de inminente publicación, que el Archivo Husserl de Lovaina ha preparado con manuscritos tardíos sobre ética, teleología y metafísica. Un título provisional del tomo es "Grenzprobleme der phänomenologischen Philosophie. Instinkt und Trieblehre, Teleologie, Theologie, späte Ethik". 
simbólicas en que nos movemos, sino también respecto de lo más arcaico, así sea enteramente fenomenológico (aquí en el sentido de pre-simbólico o preinstituido). No otra cosa vio Kant en la experiencia de lo sublime.

El bemol sobreanotado (volveremos sobre el particular) de que (acaso no) quepa una titularidad de esa libertad en ciertos niveles arquitectónicos, una empuñadura de yo en ciertos registros, es un problema que se deja declinar de modo muy fecundo a la luz de un concepto finkeano apenas utilizado y comentado en la prolija bibliografía secundaria fenomenológica, a saber, el de "anonimato fenomenologizante": hay matriz de desajuste respecto de lo fenomenológico (lo que Richir llamará "el desajuste no esquemático dentro del desajuste esquemático") en régimen de anonimato fenomenologizante. El anonimato fenomenologizante es la cifra de una matriz de libertad, propia de lo humano, que devendrá luego, arquitectónica abajo (si situamos "arriba" lo arcaico) en libertad en titularidad. Ese anonimato fenomenologizante matricialmente dará lugar a una libertad en primera persona, a su confirmación performativa. Todo está en comprender que esa confirmación performativa está espectralizada, es decir arquitectónicamente desplegada y diferida. Ese diferir arquitectónico (temporalización de una diferencia arquitectónica) es muy distinto a un diferir por diseminación según lo entiende Derrida, y donde la multiestratificación de la experiencia dista mucho de estar pensada a fondo: la fenomenología se sitúa, aquí, en las antípodas de la deconstrucción.

Nos hemos permitido un meandro a la vera del curso principal del texto. Tratemos de comprender su pertinencia pues será importante para lo que sigue, trenzado como está según un vaivén muy particular y cuya nominación adelantamos: vaivén entre teoría transcendental del método y teoría transcendental de los elementos. Preguntémonos pues: ¿de qué tipo de meandro se ha tratado? Repito que no es baladí preguntárselo toda vez que incidiremos en meandros que, precisamente, serán del mismo cariz del que acabamos de holgarnos. El de un meandro que, de habérselas con concretudes fenomenológicas, pasa a habérselas con ese habérselas. Es un tipo de meandro que, prolongando la metáfora de un río o de un curso de agua, algo tiene de contracurso o contracorriente. Fink lo llamó "teoría transcendental del método", recuperando, para la fenomenología, esa última parte de la Crítica de la razón pura de Kant 
(de la que Heidegger, por cierto, hace poco menos que caso omiso ${ }^{43}$ ) y de la que, en un contexto no estrictamente fenomenológico, tanto partido ha sacado Frank Pierobon en sus extraordinarios estudios sobre $\mathrm{Kant}^{44}$.

La genialidad de Fink en este punto consiste en haber generado una declinación propiamente fenomenológica de la teoría transcendental del método kantiana. Fenomenológicamente declinada, la teoría transcendental del método (una de cuyas "partes ${ }^{45 "}$ sería la arquitectónica fenomenológica (o las arquitectónicas fenomenológicas)) se pregunta por el quehacer filosofante y fenomenologizante, y no tanto por las concretudes fenomenológicas. Ahora bien, se hace cuestión de ello concretamente: tal y como esa pregunta surge y se espacia, toma cuerpo y holgura, aderezo, en el yo transcendental con arreglo a esa escisión -"Spaltung" nos dice Fink - llamada yo fenomenologizante, particularísimo derrotero de la Leiblichkeit de la vida transcendental, inaudita filigrana de Leiblichkeit en el seno de la meóntica de la vida transcendental, suerte de meóntica a la segunda potencia. En efecto, Fink nos dice, en su genial VIa Meditación Cartesiana, que mientras el yo transcendental se desvela, una vez hecha la reducción, como el auténtico en sí (en detrimento del mundo interpretado por la actitud natural), en sí que es para sí (que se sabe en sí), el yo fenomenologizante es, en cambio, un puro para sí: no se recoge en ser alguno, ni siquiera en la concreción meóntica de lo transcendental.

Por lo demás, ese exponente de la vida transcendental que hace que la subjetividad transcendental acceda a sí misma como transcendental constituye un determinado quehacer, un quehacer fenomenologizante que no es constitutivo ni directamente ${ }^{46}$ transcendental. Mediante este quehacer fenomenologizante se revela la esfera de lo transcendental. La vida transcendental se revela a sí misma, adviene a sí a través de este contra-movimiento fenomenologizan-

${ }^{43} \mathrm{Y}$ ello con nefandas consecuencias, como agudamente ha puesto de manifiesto Frank Pierobon en el importantísimo artículo "Le malentendu Kant/Heidegger", Epokhè 1 (número dedicado a la cuestión: "Le statut du phénoménologique") 127-202. También pueden consultarse las obras de Frank Pierobon, Kant et la fondation architectonique de la métaphysique (Grenoble, J. Millon, 1990), y Système et représentation (Grenoble, J. Millon, 1993).

${ }^{44}$ El propio Richir reconoce, al principio de sus Méditations phénoménologiques, que esa inspiración le viene del que fuera su antiguo doctorando, Frank Pierobon.

${ }^{45}$ Y habrá que ver cuál es el sentido mereológico de "parte" en el seno del vector en que consiste la teoría transcendental del método. Hemos avanzado una hipótesis sobre el particular en Pablo Posada Varela, "Introducción a Variaciones II y a otros aspectos de la fenomenología de Marc Richir".pdf, Eikasia 40 (2011) 357-441.

${ }^{46}$ A pesar de poder serlo indirectamente, a través de lo que Fink denominará "mundanización impropia" o "secundaria". Hay una interesantísima conversación con Husserl y Fink sobre este punto (primero con ambos, luego con Fink a solas) recogida por Dorion Cairns en sus Conversations with Husserl and Fink, The Hague, Martinus Nijhoff, 1976. 
te, lo cual, dicho sea de paso, le parece, a Michel Henry, poco menos que un disparate (así lo denuncia en su obra Incarnation ${ }^{47}$ ). Digamos que el fenomenologizar (según sus modalidades varias: fenomenologizar reductivo, eidético, regresivo, progresivo, constructivo) constituye la concreta articulación del "para sí" de la vida transcendental, el para sí (fenomenologizante) que adereza su en sí (transcendental); mentábamos a Fink más arriba, recordando cómo la vida transcendental es "en y para sí".

\section{ANONIMATO TRANSCENDENTAL Y ANONIMATO FENOMENOLOGIZANTE}

Ahora bien, resulta que el propio para sí fenomenologizante se escapa a/hacia/de sí mismo como para sí, se mueve más rápido de lo que la teoría transcendental del método (teoría de los movimientos fenomenologizantes) puede registrar. Estas filigranas del para sí fenomenologizante con que el fenomenologizar ya siempre se ha rebasado de continuo (sin que este rebasamiento tenga soporte ontológico ninguno: recordemos que el fenomenologizar carece de en sí, es puro para sí; o, dicho de otro modo, su "en sí" cae de nuevo a ser la propia subjetividad transcendental) se le escapan a la propia teoría transcendental del método. No es a seguirlos del todo; aún menos a anticiparlos. El fenomenologizar se hurta a sí mismo no bien se pone a hacer teoría transcendental del método: no se va a sí mismo en los alcances. Sólo parcialmente. Este retraso, suerte de huella anticipada de su movimiento, extraña sombra antecedente que irremediablemente le precede, no es otra que -lo adelantábamos más arriba y habremos de explicitarlo enseguida- el de su "anonimato fenomenologizante"; anonimato intra-reductivo y absolutamente sui generis. No se trata del anonimato transcendental, el de un Fungieren constitu-

${ }^{47}$ Cfr. Michel Henry, Incarnation. Une philosophie de la chair, Paris, Ed. du Seuil, 2000. Este disparate -le concedo a Michel Henry la apariencia de disparate que esto tiene- constituye, a mi parecer, una auténtica genialidad de Fink, algo que vio con más claridad y consecutividad que el propio Husserl, genialidad en la que - creo yo - se embosca algo muy profundo, todavía inexplorado, en la comprensión tanto de la reducción como del mundo o del par concrescente vida-mundo. Con todo, reconozco el gran libro que es Incarnation, así como la importancia y originalidad de la posición fenomenológica de Henry y, a mi parecer, el carácter imprescindible de su entera obra. $\mathrm{O}$, dicho de otro modo, reconozco la riqueza enorme que gana cualquier problema fenomenológico cuando se incluye, así sea para criticarla, la originalísima posición de Henry. La posición de Henry es, al menos, una posición, y, sobredimensionados o no, exagerados o no, su fenomenología alberga auténticos hallazgos. Merece pues siempre ser tenido en cuenta. No diría lo mismo de alguno que otro ilustre contemporáneo y compatriota suyo. 
yente que constituye y hubo instituido sin asistir a su obra. Se trata de un anonimato del reducir y en el reducir.

Ese retraso -no está de más recordarlo- es el que la teoría transcendental del método trata de recuperar. De hecho, ese retraso es su tema, es lo que, en propio, le da un espesor a la teoría transcendental del método a pesar de ser ésta, formalmente, autoreferente. Se trata de una autoreferencia diferida, y el factor de este espesor y "difiriencia" reside, precisamente, en ese retraso de la teoría transcendental del método respecto del anonimato fenomenologizante. Del mismo modo que el anonimato transcendental aporta, en cierto modo, el material de trabajo de la teoría transcendental del los elementos o "fenomenología transcendental" tal y como suele entenderse, el anonimato fenomenologizante -el retraso del fenomenologizar respecto de sí mismo- es la oscuridad por desentrañar que constituye el material sobre el que muerde la teoría transcendental del método, sobre el que va ganando, lento a lento, claridad.

El fenomenologizar ya siempre se ha puesto en juego a ciegas, ya siempre ha hecho un(o o varios) (contra-)movimiento(s) un punto antes de que hayamos podido irle en los alcances. Se trata de un anonimato que ha de explicitarse reducción-adentro, es decir, que no tiene directamente que ver con la constitución del mundo. Este anonimato es, a fin de cuentas, el tema de la teoría transcendental del método. Amanece, como decíamos, con la reducción y sólo tiene sentido en la reducción o en relación a la reducción. Eso sin perjuicio de la insituabilidad del íncipit de la reducción, de su fiat como dice Husserl en varios textos de Hua XXXIV. Se trata pues de un anonimato interno a la explicitación de la constitución transcendental (que acomete la teoría transcendental de los elementos). No es lo implícito (anonimato transcendental o fenomenológico: las síntesis pasivas, por ejemplo) que explicita el fenomenologizar, sino antes bien lo implícito de ese movimiento mismo de explicitación, lo implícito de la práctica reductiva misma (y no las implícitas constituciones que desentraña la propia reducción). 


\section{Parecencia del Genio Maligno}

En este anonimato fenomenologizante también se emboza, como veremos, el Genio Maligno ${ }^{48}$. Son los oscuros y recónditos andurriales por los que el Genio Maligno nos ronda y, en ocasiones, hostiga. ¿Cómo? Desviando el sentido, o vaciándolo de pertinencia, volviéndolo caduco y huero, tornando los entusiasmos, las ilusiones (entusiasmadas) en meras, en ilusorias ilusiones: simples quimeras $^{49}$. El Genio Maligno amortaja de antemano la Lebendigkeit de las Sinnbildungen. No las cambia en sus contenidos; antes bien hace algo sutilísimo (no sabemos qué ${ }^{50}$ ) que las vuelve caducas de antemano, que, sin matarlas (lo cual sería mucho hacer y un hacer demasiado directo para el Genio Maligno), las muere. En lo más inspirado de su diabólica "industria" (por retomar el término cartesiano), ya le ha tallado a medida el ataúd a toda nueva Sinnstiftung, y todo un punto antes de nacer. De repente, todo sentido nos nace muerto y como a trasmano en lo más profundo de su incoación, con arreglo a una traspolación que no se deja localizar dóxicamente, sólo afectivamente, y bajo el signo de un desencanto, de una suerte de creación que se nos vacía de entusiasmo en las manos.

Es como si el Genio Maligno se hubiera apropiado la incoación de la modificación de neutralidad y, sin tocar los contenidos (recordemos que la modifica-

\footnotetext{
48 Desde esa franja a trasmano del anonimato fenomenologizante mueve sus hilos el Genio Maligno, acciona sus "palancas". Acaso esas mismas palancas ("Hebel") de que nos habla Husserl en la $3^{a}$ Investigación lógica cuando nos dice, de los conceptos de "todo" y de "parte", aún faltos de elucidación, que han de servir "en cierto modo de palanca" ("als Hebel dienen müssen"). Y quizá -dejémoslo para el trabajo que seguirá a éste- la malignidad del Genio Maligno pueda tener también una descripción mereológica y la mereología, aparte de un uso fenomenológico y arquitectónico (concretizante o concrescente), lo tenga también, por así decirlo, "diabólico" (desconcretizante y contra-concrescente), suerte de matriz fenomenológica de lo que sería el uso metafísico y sistemático sobre el que nos detendremos en la parte final de este artículo.

${ }^{49}$ Esta virazón de entusiasmo a quimera, ínsita en el sentido español de "ilusión", está muy presente en los poemas de Antonio Machado. De hecho, "quimera" es una palabra que se repite en varias ocasiones en los poemas de Soledades y Galerías.

${ }^{50}$ Como nos dice Antonio Machado de la figura de la Muerte en ese poema en que evoca la muerte de Leonor, el poema "CXVIII" de Campos de Castilla: "[...] / Se fue acercando a mi lecho / -ni siquiera me miró-, / con unos dedos muy finos / algo muy tenue rompió. / Silenciosa y sin mirarme / la muerte otra vez pasó / delante de mí. ¿Qué has hecho? / La muerte no respondió".

Evidentemente, otro tema apasionante estaría en distinguir (todo lo claramente que se pueda) las matrices fenomenológicas de esa figura de la muerte y de la figura del Genio Maligno. Y bien lo supo o intuyó Husserl, de cuya pared, frente a la mesa de trabajo, colgaba una reproducción del Ritter, Tod und Teufel de Durero. Muerte y Genio Maligno no son lo mismo ni acaso (se) jueguen en los mismos quicios, a pesar de que, a veces haya traspolaciones.

En García Lorca, la Muerte cobra caracteres propios del Genio Maligno, por ejemplo en la célebre "Canción del Jinete", caracteres de malignidad y astucia que hacen que nos avengamos a sus propósitos en virtud de nuestro esfuerzo por querer evitarlos. El "Duende", en cambio, no tiene, en García Lorca, ese matiz de malignidad diabólica. Es más bien lo que, incomodando, permite una creación, la exaspera (cfr. el precioso ejemplo de Goya en la conferencia de García Lorca "Juego y teoría del Duende").
} 
ción de neutralidad es una modificación conforme ${ }^{51}$ ) los vaciara de fuerza, los volviera, como nos dice Husserl en el célebre $\S 114$ de Ideas I dedicado a la modificación de neutralidad "contra-nóemas", "contra-esencias" y "sombras de acto" ("Schatten von einem Akte"):

Todo cogito tiene una contrafigura exactamente correspondiente de tal índole que su nóema tiene su contranóema exactamente correspondiente en el cogito paralelo.

La relación entre los "actos" paralelos consiste en que uno de los dos es un "acto real", el cogito es un cogito "real", "realmente ponente", mientras que el otro es la "sombra" de un acto, es un cogito impropiamente tal, un cogito no "realmente" ponente. El uno efectúa realmente, el otro es el mero espejismo de un efectuar. ${ }^{52}$

Husserl, en paralelo a este texto de Ideas I, llevaba ya tiempo confeccionando lo que luego, junto a Langrebe, ambos recogerían bajo el rótulo de Studien zur Struktur des Bewusstseins, grupo de manuscritos de los que, afortunadamente, parece que pronto habrá una edición. El texto n¹5 de Hua XXIII está, en su mayor parte, sacado de ese proyecto de publicación. Hay partes, en ese texto, donde se estaba cocinando lo que luego, en Ideas I, tratará de presentarse como doctrina en punto a la modificación de neutralidad. Hay por ejemplo, en el texto n015, una fluctuación en la terminología (que luego se estabiliza en Ideas I) para captar la conciencia neutral. Una fluctuación entre los

${ }^{51}$ Aunque esto, si bien se piensa, no está tan claro. Si nos referimos al extraordinario texto n²0 de Hua XXIII, comprobamos que hay una neutralidad espontánea, una neutralidad propia, por ejemplo, de la reine Phantasie y que, cuando es pasivamente "ejecutada" por lo que Husserl llamaba un versunkenes Ich sí es reduplicable (aunque sólo una única vez), contrariamente a lo que pasa con la neutralidad como modificación conforme que, como sabemos, no es (a diferencia de la modificación por imaginación) iterable. Este matiz en la neutralidad (que distingue neutralidad espontánea de la Phantasia y neutralización de una doxa como modificación conforme) es esencial para comprender la diferencia entre "Phantasie" e "Imagination" o, si se quiere, la diferencia entre "Phantasie" y "Einbildungskraft", término, éste último, que, en Husserl, es prácticamente sinónimo de "Imagination". Dicho esto de pasada y mal les pese algunos heideggerianos demasiado entusiastas con Kant y el problema de la metafísica. Efectivamente, Heidegger ni rozó siquiera la profundidad y el particularísimo tipo de concretud que se esconde en lo que Husserl entendía por "Phantasie". Lo que Husserl está tratando de pensar bajo el término "Phantasie" es algo radicalmente nuevo en la historia de la filosofía (acaso no en la historia de la literatura); es, de hecho, las más veces, una intuición (esta de la radicalísima especificidad de la Phantasie) que se le escapa, que no consigue estabilizar conceptualmente. Para una explicitación de estos dos tipos de neutralidad, cfr. Pablo Posada Varela, "Hipérbole y concretud en parpadeo: en torno al último libro de Marc Richir "Variaciones sobre el sí mismo y lo sublime".pdf, Eikasia 34 (2010), sobre todo las pp. 440444.

52 Edmund Husserl, Ideas relativas a una fenomenología pura y una filosofía fenomenológica, México, Fondo de Cultura Económica, 1993, p. 270. Trad. José Gaos. En adelante, Ideas I.

El texto original dice:

"Zu jedem cogito gehört ein genau entsprechendes Gegenstück derart, daß sein Noema in dem parallelen cogito sein genau entsprechendes Gegennoema hat.

Das Verhältnis der parallelen 'Akte' besteht darin, daß der eine von beiden ein 'wirklicher Akt' ist, das cogito ein 'wirkliches', 'wirklich setzendes' cogito, während der andere 'Schatten' von einem Akte, ein uneigentliches, ein nicht 'wirklich' setzendes cogito ist. Der eine leistet wirklich, der andere ist bloße Spiegelung einer Leistung". Hua III/1 259. 
pares "Axiose", "Anaxiose"-/ "Inaxiose"53 de un lado, y "Aktualität", "Inaktualität" de otro. Esta última distinción (correspondiente a la llamada "modificación de inactualidad") será ya, en el $\S 115$ de Ideas $I$, claramente distinguida de la "modificación de neutralidad". Todo ello se hace en la continuidad del impresionante esfuerzo analítico que pone en juego Husserl para deslindar la inaudita especificidad de la modificación de neutralidad. Esfuerzo que ya arranca desde los $\S \S 109$ y 110 en que distingue la operación de neutralización de las operaciones de duda, de negación o de suposición. Éstas no serían sino modalizaciones dóxicas (y no modificaciones; de ahí que, por ejemplo, quepa aplicar la modificación de neutralidad sobre, por caso, una modalización dóxica de duda o un entero tramo de modalizaciones). Los primeros textos editados en Hua XXXIV han añadido detalles interesantísimos atinentes a esta problemática.

Los conceptos de "Axiose" o "Anaxiose" / "Inaxiose" (donde aparece claramente el contexto teórico propio de los Studien zur Struktur des Bewusstseins ${ }^{54}$ ) desaparecen de estos párrafos de Ideas $I$, pero son el claro trasunto de esta modificación de neutralidad que no es acto de veras sino sombra de acto, que no vive de veras en los actos ni está a las cosas que pone, sino que se limita a transportarse cabe ellas en el mero pensamiento ${ }^{55}$, como quien las toca no de forma efectiva ${ }^{56}$, sino fantasmáticamente, con desgana o indiferencia (o in-

${ }^{53}$ Hay, a su vez, una fluctuación terminológica entre "Anaxiose" e "Inaxiose" a lo largo del texto 15 de Hua XXIII. Fluctuación que, al correr del texto, parece resolverse a favor de la opción "Inaxiose".

54 Saludamos desde la más profunda admiración el interesantísimo trabajo de exégesis que de estos textos lleva años haciendo Antonio Zirión. También la prometedora tesis que sobre estos textos y asuntos de la afectividad prepara Ignacio Quepons.

55 "Los casos se distinguen, pues, radicalmente porque la correspondiente protodoxa es, o una protodoxa real, una creencia creída realmente, por decirlo así, o bien su inerte contrafigura, el "mero pensar" (en el ser puro y simple, en el ser posible, etc.)". Ideas $I$, pp. 271s.

"Es scheiden sich nun die Fälle radikal dadurch, daß die jeweilige Urdoxa entweder eine wirkliche ist, sozusagen ein wirklich geglaubter Glaube, oder aber sein kraftloses Gegenstück, das bloße 'sich denken' (von Sein schlechthin, Möglichsein usw)". Hua III/1 261.

${ }^{56}$ Acaso porque no las puede tocar, como les pasa a los muertos en vida, a los fantasmas; temática, esta última, muy presente en Unamuno - por ejemplo en Niebla (de cuyo prólogo ha hecho Richir, por su lado, una lectura muy profunda)- o, desde luego, en Bergamín. Por otro lado, podemos referirnos al extraordinario texto de Yasuhiko Murakami, "Sobre la disociación en el momento de la experiencia traumática", que aparece en este mismo volumen de Investigaciones fenomenológicas, y que usaremos, en relación con estos inquietantes párrafos de Ideas $I$, en el contexto de una segunda parte de este artículo. 
cluso desesperanza) ${ }^{57}$, y por medio de esas sombras de acto que lo son de sombras de posiciones ("Schattensetzungen") ${ }^{58}$.

Cosa distinta es que luego la neutralidad pueda ser re-investida de interés teórico cuando (1) se universaliza en la epojé (primer paso al límite, y se estudian a fondo algunos manuscritos recogidos en Hua XXXIV) y, a su vez, y como parte de la epojé, (2) pasa a formar parte del acto y proyecto global de la reducción (segundo paso al límite, tocante, esta vez, a la epojé, y sólo indirectamente ${ }^{59}$ a la modificación de neutralidad). De este modo, el acto global de la reducción le transmite a la infinita desgana e indiferencia (ambas cosas laten en el sentido de "Inaxiose" o "Anaxiose") de la pura neutralidad otra teleología, una teleología (la de la fundamentación absoluta bajo la especie de la elaboración de la fenomenología transcendental) que ya no es, evidentemente, la teleología neutralizada de la posición dóxica, sino que, precisamente, saca partido de la neutralización de esa teleología Geradehin, la de la constitución de mundo.

Es como si el Genio Maligno se inmiscuyese en los quicios más profundos y a trasmano de la vida transcendental ${ }^{60}$ para instilar, moviendo ignotas palancas $^{61}$, una neutralización anterior a toda voluntad e incluso conciencia, la neutralización que corresponde a la pura desesperanza, irrecuperable para cual-

\footnotetext{
${ }^{57}$ Cfr. el texto de Yasuhiko Murakami en este mismo volumen. También, evidentemente, sería interesante establecer, desde estas coordenadas, un diálogo con el tratamiento fenomenológico que de la cuestión de la desesperanza viene haciendo, desde hace tiempo, Miguel García-Baró. De la desesperanza en su constelación con la dificilísima problemática del dolor (propio y ajeno) y de lo que sería el dolor máximo: no tanto la desesperanza propia cuanto la desesperanza vista en el prójimo (y nuestra ineludible parte de responsabilidad en la cristalización -y sostenimiento- de la desesperanza en el otro).

58 "De antemano está, pues, prescrito [modifico aquí la traducción] en la esencia de toda vivencia de conciencia un conjunto fijo de posiciones de ser potenciales, $y$, según la índole que tenga de antemano la conciencia respectiva, un campo de posibles posiciones reales o de posibles "sombras de posiciones" neutrales." Ideas I, p. 272.

"Von vornherein ist also im Wesen jedes Bewußtseinserlebnisses ein fester Inbegriff potentieller Seinssetzungen vorgezeichnet, und zwar, jenachdem das betreffende Bewußtsein von vornherein geartet ist, ein Feld möglicher wirklicher Setzungen oder möglicher neutraler 'Schattensetzungen"'. Hua III/1 261.

${ }^{59}$ Como parte remota o mediata, diría Husserl en la terminología de la $3^{a}$ Investigación lógica.

${ }^{60}$ En una segunda parte de este artículo trataré de mostrar con precisión (precisión que quisiera que fuese mereológica) cómo y en qué quicios.

61 "Hebel" dice Husserl en la $3^{a}$ Investigación lógica. Y no volvemos a usar este término, aquí, y en relación con el Genio Maligno, por casualidad. Si tenemos presente lo que más arriba dijimos sobre el anonimato fenomenologizante, y sobre cómo el Genio Maligno azuza desde esa franja, entenderemos, más adelante, cuando establezcamos la relación entre esa "palanca" que es la mereología y el fenomenologizar (como quehacer arquitectonizante), cómo el Genio Maligno mueve sus hilos y acciona sus palancas precisamente desde ese anonimato fenomenologizante que nos es, indefectiblemente, siempre a trasmano. El anonimato fenomenologizante infarta, en la Spaltung, una irremediable fragilidad que nos expone, de parte a parte, al Genio Maligno o, lo que viene a ser lo mismo, a las varias formas de reificación psicótica de esa Spaltung y que, no hace mucho, solía, solo que desde otra institución simbólica, entenderse como "posesión". Tratamos, simplemente, de hollar las matrices fenomenológicas que luego recubren una u otras instituciones simbólicas.
} 
quier teleología, perdida de antemano para cualquier entusiasmo (e incluso contaminante de cualquier entusiasmo, des-entusiasmante, no tanto nada pura cuanto "voluntad de nada" como nos dice Bergamín del Demonio ${ }^{62}$ ). José Bergamín ve con extraordinario tino que toda auténtica creación, institución de sentido, se erige contra esta inercia de desesperanza y resaca de nada que instila el Genio Maligno (lo que, mutatis mutandis, Bergamín llama el Demonio).

Eso mismo experimentaron otros poetas y creadores. Sabemos como el talento, sencillamente descomunal, de un Hugo von Hofmannsthal, deja, un día, de querer producir poesía. Se instala la desgana. A veces depresiones que pudren el alma. Muchas veces transidas de angustiosas somatizaciones. No otra cosa es la sobrecogedora Carta a Lord Chandos: la descripción de una modificación de neutralidad que nadie había convocado y que, de repente, se apodera de cualquier entusiasmo y lo devuelve vaciado, como una "camisa de serpiente", por recuperar las palabras de la cita de Bergamín que hacíamos en un párrafo anterior. Neutralidad que no es parte de ninguna otra teleología y a cuya incoación no parecemos poder remontarnos, como si ella ya incluyese, pre-neutralizado, todo esfuerzo de remontada al supuesto quicio en que las cosas se desviaron. Von Hofmannsthal consigue, mal que bien, compartimentar su desesperanza y ganar, para futuros entusiasmos, compartimentos estancos. Ahora bien, serán compartimentos estancos de "entusiasmo" tocados por cierto descreimiento. Tras la hiperbólica neutralización que se lleva por delante su vivir poetizando, la Reellität misma de su poesía (que, nos dice, ya no siente, ya no se cree), se repone, más o menos, de la dramática experiencia que, apócrifamente, narra en la Carta a Lord Chandos. Sea como fuere, prosigue su actividad literaria despejándole un compartimento al teatro, también al ensayo. Así y todo, y por talentosas que sean esas producciones, ya no tendrán la fuerza de los poemas ${ }^{63}$.

Un personaje como Rimbaud, que era bastante menos sereno, tuvo un aterrizaje más proceloso desde el cielo (Illuminations) o el infierno (Une saison en enfer) de su quehacer poético. Genial y precoz como von Hofmannsthal aunque, eso sí, menos sereno, también se las vio con la inopinada neutralidad de

62 José Bergamín, La importancia del demonio, Madrid, Siruela, 2006.

63 Parece como si Hugo von Hofmannsthal se hubiese mundanizado, hubiese renunciado a cierto absoluto, y se hubiera hecho a los discursos del mundo trenzados, como señala en ocasiones GarcíaBaró en sus trabajos, de historiografía y, al cabo, de sofística. Embates y triunfos locales. 
un súbito descreimiento. Descreimiento que en él se cobró dedicarse al contrabando de armas en Etiopía (actividad, por cierto, en la que no destacó: puede que su soberbia no le dejase ver o reconocer que había quienes -compañeros de profesión- contrabandeaban con réditos muy superiores y a costa de mucho menos esfuerzo) y, pasado un tiempo, una muerte precoz, dolorosa y trágica.

Con lo que ha corrido la suerte (más aún si es suerte inopinada, que no podemos controlar) de una modificación de inaxiosis (por hablar en los términos del texto n¹5 de Hua XXIII), nada puede hacerse, ninguna creación puede sostenerse, nada decirse ni pensarse ni emprenderse que sean otra cosa que ese mismo decir, pensar, emprender, puras sombras indiferentes a las que nada responde allende ${ }^{64}$, a las que nada resiste pues eso son: meras sombras o Fikta ${ }^{65}$ de acto, sombras o Fikta de posición). Los corchetes con el término original subrayan lo que en la traducción española no siempre queda claro, pero que entendemos que tiene una profunda relación con la cuestión del Fiktum tal y como se trata en Hua XXIII:

Y, una vez más, la conciencia en general es de tal índole que es de un doble tipo: realidad y sombra, conciencia posicional y conciencia neutral. La una caracterizada porque su potencialidad dóxica conduce a actos dóxicos realmente ponentes, la otra porque sólo da de sí sombras [Schattenbilder] de semejantes actos, sólo modificaciones de neutralidad de éstos, con otras palabras, en su contenido noemático no encierra absolutamente nada apresable dóxicamente, o lo que es equivalente una vez más, no encierra ningún nóema "real", sino sólo una contrafigura [Gegenbild] de éste. ${ }^{66}$

64 José Bergamín, en una carta a María Zambrano del 22 de Julio de 1957 le manda una serie de poemas. Citaremos uno de ellos más adelante. Por ahora, en consonancia con estos textos de Husserl leamos dos de ellos: "-Yo quiero la realidad; / no quiero sombras ni sueños. / Quiero verdades que estén / fuera de mi pensamiento". Dictamen sobre el que el Genio Maligno también parece echar su manto de neutralización cuando Bergamín (en esta lucha a brazo partido que mantiene con el Genio Maligno a lo largo de toda esta carta a María Zambrano) escribe, inmediatamente después, la siguiente estrofa: "Esas verdades que están / fuera de tu pensamiento / son la verdad de tus sombras, / la realidad de tus sueños". José Bergamín, Dolor y claridad de España. Cartas a María Zambrano, Sevilla, Editorial Renacimiento, 2004, pp. 33s. Edición de Nigel Dennis.

${ }^{65}$ Por recuperar otro término esencial de Hua XXIII relativo a la conciencia de imagen y a la imaginación, no a la Phantasia.

${ }^{66}$ Ideas $I$, p. 272.

Los subrayados en el texto alemán son nuestros. "Und wieder: so geartet ist Bewußtsein überhaupt, daß es von einem doppelten Typus ist: Urbild [es decir: que precisamente no se trata de un Bild, sino del 'original', es decir, como traduce Gaos, de la 'realidad'; sí son meros reflejos, como veremos, los correspondientes neutralizados de estos originales o Urbilder] und Schatten, positionales Bewußtsein und neutrales. Das eine charakterisiert dadurch, daß seine doxische Potentialität auf wirklich setzende doxische Akte führt, das andere dadurch, daß es nur Schattenbilder solcher Akte, nur Neutralitätsmodifikationen von solchen aus sich hervorgehen läßt; m.a.W. daß es in seinem noematischen Bestand gar nichts doxisch Faßbares enthält, oder was wieder gleichwertig ist, daß es kein 'wirkliches' Noema, sondern nur ein Gegenbild eines solchen enthält". Hua III/1 261. 
Es ese dar igual de la modificación de neutralidad (parangonable al Il y a levinasiano ${ }^{67}$ ) aquello a que se refiere Husserl en estas conocidísimas líneas del $\S 110$ de Ideas $I$ :

Que aquí [en la modificación de neutralidad] se está realmente ante una peculiaridad incomparable de la conciencia se muestra en que las nóesis propiamente tales, noneutralizadas, están por su esencia sujetas a una "legitimación por la razón", mientras que para las neutralizadas no tiene sentido alguno la cuestión de la razón y la sinrazón. Igual y correlativamente pasa con los nóemas. Todo lo caracterizado noemáticamente como existente (cierto), como posible, conjeturable, cuestionable, nulo, etc., puede estar caracterizado así en forma "válida" o "no válida", puede ser, ser posible, no ser nada, etc., "en verdad". En cambio, el mero pensar no "pone" nada, no es conciencia posicional. El "mero pensamiento" de una realidad, una posibilidad, etc., no "pretende" nada; no cabe ni reconocerlo por justo, ni rechazarlo por injusto. ${ }^{68}$

Todo se convierte en pura sombra y no queda sino pura indiferencia. Pura indiferencia en el mejor de los casos. En el peor -caso de fijación de la Spaltung fenomenologizante (de que nos habla Fink en su VIa Meditación cartesiana)- se instala la desesperanza. Una desesperanza sin garantía de que no sea para siempre y sin remedio, huera de entusiasmo, irrecuperable para toda teleología. Sufriente desesperanza cuando esa indiferencia y desgana vienen instiladas desde un quicio -que no es otro que la Spaltung fenomenologizante de en mi vida transcendental (cfr. Fink) - que el Genio Maligno, de un modo u otro $^{69}$, ha conseguido, ya de entrada, $\operatorname{controlar}^{70}$, y desde el que, moviendo

${ }^{67}$ Cfr. Yasuhiko Murakami, op. cit.

${ }^{68}$ Ideas I, p. 259.

"Daß hier [in der Neutralitätsmodifikation] wirklich eine unvergleichliche Eigentümlichkeit des Bewußtseins vorliegt, zeigt sich daran, daß die eigentlichen, nichtneutralisierten Noesen ihrem Wesen nach einer 'Rechtsprechung der Vernunft' unterliegen, während für die neutralisierten die Frage nach Vernunft und Unvernunft keinen Sinn gibt. Ebenso, korrelativ, für die Noemen. Jedes noematisch als seiend (gewiß), als möglich, vermutlich, fraglich, nichtig usw. Charakterisierte kann 'gültiger'- oder 'ungültiger' weise so charakterisiert sein, es kann 'in Wahrheit" sein, möglich sein, nichtig sein usw. Hingegen das bloße Sich-denken 'setzt' nichts, es ist kein positionales Bewußtsein. Der 'bloße Gedanke' von Wirklichkeiten, Möglichkeiten usw. 'prätendiert' nichts, er ist weder als richtig anzuerkennen, noch als unrichtig zu verwerfen". Hua III/1 249.

69 Para empezar, a través de la superstición como nos dicen Kant de un lado (en La religión dentro de los límites de la mera razón) y Bergamín de otro (en La importancia del Demonio o en El pozo de la angustia entre otros textos). Superstición con la que pretendemos protegernos, pero a través de la cual acabamos siempre siendo víctimas del Genio Maligno. La psicosis y las neurosis nacen también de un intento desaforado de sobreprotección frente a lo indeterminado, en definitiva, frente a la realidad (como aquello -nos dice Maldiney- que no nos esperábamos). Nacen, en suma, del miedo, y producen, como ha mostrado Henri Maldiney en sus trabajos, un cierre de la "transpasibilidad" fundado en una suerte de miedo protoontológico a lo que él llamo lo "transpossible".

70 Por retomar un concepto de mi anterior trabajo "Concrétudes en concrescences", el Genio Maligno ha conseguido apropiarse de lo que allí llamo "cinestesia fenomenologizante", (me) manipula (desde) mi propia "cinestesia fenomenologizante".

Por lo demás, y a la espera de su próximo libro sobre fenomenología de lo político (en que Genio Maligno y Tirano se pondrán en íntima relación), puede consultarse con provecho el siguiente artículo de Marc Richir: "Doute hyperbolique et machiavélisme. Institution du sujet moderne chez Descartes".pdf, Archives de philosophie (1997). 
ciertos hilos, accionando determinadas palancas, nos manipula mereológicamente "de parte a parte"71.

Por retomar lo que adelantábamos líneas más arriba, al comienzo de este epígrafe, es como si el Genio Maligno, sin trocar los contenidos de nuestros pensamientos $^{72}$, vaciara de per-tinencia el hecho, la cuestión (siquiera) de que fueran verdaderos o falsos y desplazara la duda -hiperbolizándola- a algo mucho más inquietante, a otra cuestión (previa) que (si prende) pudre de raíz toda verdad e incluso -insistimos- vuelve caduca la cuestión misma de la verdad o la falsedad de dichos pensamientos ${ }^{73}$. ¿Cómo (nos la juega el Genio Maligno)? Desplazando la duda no ya al hecho (o no) de que nuestros pensamientos sean verdaderos (o falsos) sino al hecho, previo, de que nuestros pensamientos sean (o no) verdaderos pensamientos ${ }^{74}$ ( $y$ no simulacros de pensamiento, pensamientos pensados por el Genio Maligno (o por el Intelecto Agente ${ }^{75}$ ), pensamientos que el Genio Maligno me envía, induce en mí, luego simulacros de pensamientos, pensamientos que sólo en apariencia son míos, vida -si interpretamos "pensamiento" y "pensar" en el amplio sentido que "cogitare" tiene en Descartes- que sólo en apariencia sería vida propia, y ello incluso en lo más profundo de su "Reellität", de su carácter reell).

De ahí que esa insensatez redoblada que la epojé hiperbólica supone (y que se añade a la previa insensatez de la epojé fenomenológica) no sea, en rigor -contrariamente a la epojé fenomenológica- ejecutable del todo, vivible hasta el fondo, ni tenga una teleología clara ${ }^{76}$, reconocible, re-efectuable, y sobre la

71 ¿Mereológicamente? Contramereologizando y contraconcresciendo.

72 Cfr. el fundamental texto de Sacha Carlson, "El cartesianismo de Richir. Aproximación a la 'Tercera Meditación Fenomenológica'", publicado en este mismo volumen de Investigaciones enomenológicas.

${ }^{73}$ Suplantándola por la cuestión previa -si se hiperboliza, si prende su hiperbolización- no ya de la verdad o de la falsedad, sino del engaño.

${ }^{74}$ No me detendré más en esto pues será uno de los temas centrales de la segunda parte de este artículo. De todas formas, se podrá encontrar, en una nota del traductor del extraordinario artículo de Sacha Carlson, una explicitación de este punto; y sobre la suplantación de la cuestión (epistémica) de si son nuestros pensamientos verdaderos o falsos por la previa cuestión de si nuestros pensamientos son verdaderos o falsos pensamientos, no pensamientos de verdades (cuestión del error y cuestión de contenidos) sino pensamientos de veras, de veras pensados (cuestión del engaño o la engañifa y de la (verdad de la) facticidad del pensar, de su estatuto ontológico). Remitimos también, por anticipado, al artículo que Sacha Carlson publicará próximamente en Eikasia, en el mencionado número dedicado a Richir, y que tratará sobre una de las formas del simulacro ontológico que la epojé hiperbólica trata de desleír, a saber, lo que Sacha Carlson Ilama la "reducción spinozista". El artículo es un interesantísimo diálogo entre Richir y Michel Henry mediado por Spinoza ( $y$, evidentemente, por la genial interpretación que de Spinoza hizo en su tesis Michel Henry).

${ }^{75}$ Como le señaló en una ocasión Iván Galán a Marc Richir en una memorable conversación en La Rochegiron.

${ }^{76}$ Aquilatada por una "Besinnung", como nos dice Husserl. Remitimos aquí a los trabajos de Iván Galán sobre la profunda relación entre Husserl y Fichte. 
que construir cupiere (como tampoco, en propio, una reconocible aisthesis epifenomenológica). Nada puede edificarse sobre el "cogito hiperbólico". Reina una continua "puesta a cero"77 del contador de las Sinntiftungen: apenas erigidas se desbaratan. Que la hipérbole fenomenológica nimba con la desesperanza siendo al tiempo su secreto y más profundo contradistinto es cosa que habrá que mostrar en otro lugar ${ }^{78}$. La hipérbole no puede ejecutarse hasta el fondo y sin embargo, y como quiera que sea, prende. Prende generando concrescencias inauditas (que sólo la hipótesis del Genio Maligno permite desenclavar) o prende, si dicha hipótesis se reifica, fijando la Spaltung deshumanizante (Fink) y gripando de raíz la cinestesia fenomenologizante (cuando no malversándola -i.e., induciendo contra-concrescencias por medio de simulacros- que es, precisamente, lo que hace el Genio Maligno: malversar). La hipótesis del Genio Maligno es absurda, insostenible, invivible. Y, sin embargo, hay un núcleo recóndito en la cuestión fenomenológica de la encarnación, un nudo por desentrañar que hace que, con todo lo absurda y redomadamente insensata que sea, la duda hiperbólica cartesiana prenda, siquiera en parpadeo. Y prenda a un nivel concretísimamente fenomenológico (donde quizá auténtico pensar e ilusión transcendental no puedan deslindarse). Que la duda hiperbólica y la hipótesis del Genio Maligno prendan es lo que hace que, por ejemplo, ciertos poemas prendan, que las hipérboles unamunianas (por ejemplo, en Niebla o en Vida de Don Quijote y Sancho) no sean meras palabras, simples contradicciones.

José Bergamín, en carta del 22 de julio de 1957, desde su humilde habitación de la Casa de México de la Cité Internationale Universitaire de Paris ${ }^{79}$, le manda a su querida amiga María Zambrano este poema, que le presenta con las siguientes palabras:

Óyeme estas últimas coplillas que me salen de más allá de mí mismo, como las otras del Cancionerillo, que llamo del Duende ${ }^{80}$ por eso. Del Duende y no del Ángel. (Andaluces los dos.) Y son así:

\footnotetext{
77 "Remise à zéro", nos dice Richir en la última sección de Phénoménologie en esquisses. Nouvelles foundations, Grenoble, J. Millon, 2000.

${ }^{78}$ Quizá asistidos por el genial ensayo de José Bergamín, "La decadencia del analfabetismo", en La importancia del Demonio. Efectivamente, la puesta a cero continua que induce la epojé hiperbólica comunica con lo que Bergamín entiende como una posibilidad diabólica de la racionalidad, con el aspecto laberíntico del sentido. Ver, sobre todo, José Bergamín Mangas y capirotes. España en su laberinto teatral en el siglo XVII, Madrid, Plutarco, 1933.

${ }^{79}$ A unos pocos pasos del lugar desde el que estoy, ahora mismo, tecleando estas líneas: la Fundación de Alemania o "Maison Heinrich Heine", en la Cité Internationale Universitaire de Paris.

${ }^{80}$ Se refiere José Bergamín a su libro de poemas, Duendecillos y coplas, Santiago de Chile / Madrid, Cruz del Sur, 1963.
} 
-Ése que tú te crees que eres tú mismo, Ése que tú te crees que llevas dentro, No eres tú, ni es tu vida, ni es tu alma, $\mathrm{Ni}$ siquiera es la sombra de tu cuerpo. -¿Pues quién es ese yo que yo no soy? ¿En qué puede serme sin yo serlo? -Pregúntaselo al otro, al que dejaste Por la senda perdida de tu sueño. ${ }^{81}$

Tener que bregar con el Genio Maligno o, si se quiere -tal y como hace José Bergamín en este poema, en la carta toda a María Zambrano- tener que bregar con una figura del Demonio o con su matriz fenomenológica ${ }^{82}$ (al punto de dejar prender y ser prendido por preguntas tan insensatas como "¿En qué puede serme sin yo serlo?"), he ahí el precio que la radicalización de la reducción fenomenológica se cobra, la íntima congoja (por hacer resonar este término unamuniano) con que la epojé fenomenológica hiperbólica se salda. No otra cosa es la radicalización hiperbólica -profundamente cartesiana, en suma- de la reducción, su secreta teleología, su teleología hiperbolizada. Puesto que se trata, en últimas, de una radicalización, entiende ésta no separarse un ápice del espíritu husserliano. Eso al menos preconiza Marc Richir ${ }^{83}$ : no difractar del espíritu (de la letra husserliana también) sino más bien incidir en él (leerla a ella en serio, y entre líneas). Incidir como hace el propio Husserl en ocasiones y de modo más o menos operatorio. Momentos vertiginosos en los textos de Husserl (vertiginosos de verdad, y no de vértigo retórico e impostado, como los de cierto discípulo) en que nos encontramos con auténticas travesías de ese cogito hiperbólico, con auténticos trances de hiperbolicidad las más veces acallados o

81 José Bergamín, Dolor y claridad de España. Cartas a María Zambrano, p. 32.

82 De ahí que quepa recuperar fenomenológicamente lo esencial de las extraordinarias intuiciones contenidas en la conferencia de José Bergamín, "La importancia del demonio". Cfr. José Bergamín, La importancia del demonio.

Obviamente no se trata de dirimir, y menos en fenomenología, si existe o no el Demonio (tampoco es ese, claro está, el propósito de Bergamín). Se trata de despejar la matriz fenomenológica que, sin indicar nada sobre la existencia del Demonio, hace que su antojo o su hipótesis, la mera consideración de su existencia, en cierto modo prendan, prendan como no lo hace una imaginación cualquiera. Las intuiciones sobre la matriz fenomenológica de la superstición, y su relación con el demonio, son, en ese texto de Bergamín, profundísimas. Es una pena que, quizá arrastrado por manías de su maestro oficioso Unamuno (manías que a Ortega le incomodaban sobremanera en Don Miguel), José Bergamín sea, en ese texto ( $y$ en otros) algo injusto con Kant. No serlo le hubiera permitido un diálogo fructífero con Kant sobre cuestiones que el filósofo de Königsberg también vio con enorme profundidad. Para empezar, esa de la superstición. Para seguir, la de lo diabólico de un lado, la del mal radical de otro.

${ }^{83}$ Véase el extraordinario texto de Sacha Carlson, en este mismo volumen. También se puede consultar el extraordinario artículo de Luís Antonio Umbelino y en el citado número de Arbor sobre fenomenología coordinado por A. Serrano de Haro. Cfr. Luís António Umbelino, "Sobre a Stimmung. Biranismo e Fenomenologia".pdf, Arbor. Ciencia, Pensamiento y Cultura vol. CLXXXV, 736 (2009). 
sobre los que se pone sordina ${ }^{84}$. En otras palabras: Richir ha recuperado la duda hiperbólica cartesiana -inseparable de la comparecencia ${ }^{85}$ del Genio Maligno- en nombre y loor del espíritu de la fenomenología de Husserl. En nombre de ese espíritu, ha criticado Richir que la fenomenología husserliana cometiera, en la letra, injusticia en su relectura de Descartes.

Evidentemente, esto tiene una profunda relación con el enorme calado de no adherencia (calado absoluto, calado, precisamente, hiperbólico) que configura lo propio de lo humano, su gracia y desgracia. No adherencia no ya respecto al sentido instituido o a las cosas, sino incluso respecto de lo más profundo de su experiencia, respecto de la vida propia ya desde su cariz de reell, de mera y muda ingrediencia de inmanencia. Evidentemente, Michel Henry, contrariamente a Richir, sí le corta aquí el paso al Genio Maligno, se lo corta exactamente en el umbral de mi pertenencia o adscripción a lo reell de la vida. No hay desajuste o intersticio (écart) en la autoafección por el que el Genio Maligno pueda inmiscuirse para jugárnosla. No hay, sencillamente, Spaltung fenomenologizante, como sí la hay en Husserl (o en Fink). Sin embargo, Husserl y Fink, al igual que Michel Henry, también le cortan el paso al Genio Maligno en este umbral (de lo reell), aunque lo hagan de modo distinto. La diferencia estriba, precisamente, en que tanto Husserl como Fink sí reconocen un exponente fenomenologizante que está en una relación de diferencia (en la identidad) con la vida transcendental, lo cual (i.e. esta diferencia entre las vidas transcendental y fenomenologizante) resulta a ojos de Michel Henry una perfecta insensatez. De ahí que Husserl le ponga un freno, en el sobrecogedor $\S 114$ de Ideas $I$, a esta hiperbólica fictualización de la modificación de neutralidad ${ }^{86}$ que amenaza con arruinar

${ }^{84}$ No hace falta acudir a manuscritos. Ejemplo de ello es el establecimiento -precisamente sobre fondo de hipérbole- de lo que Ilama Husserl, en Erste Philosophie II, "apercepción metódica". La apercepción metódica sutura como puede un hilván de hiperbolicidad.

85 Digo bien "comparecencia" y no, ipso facto, reificación psicótica. O, por decirlo con una preciosa palabra del español, "parecencia" y no presencia. La parecencia del Genio Maligno ya induce efectos de concrescencia inauditos. Como sugiere Bergamín, coalescente con la hiperbolización de la duda es la mera parecencia del Genio Maligno. En cambio, consectaria de la superstición es presencia de éste, la certeza o evidencia (llega a decir Bergamín) de su presencia. La superstición tiene algo de confirmación performativa. La parecencia del Genio Maligno en la duda hiperbólica no. Parecencia que, por cierto, es fenomenológicamente más que un blosses Meinen, i¿más?!, bien pero, ¿entonces qué?

${ }^{86}$ Somos conscientes de que no se ha de confundir la modificación de imaginación (o puesta en imagen) con la simple (schlichte, blosse) modificación de neutralidad. "Simple" porque la modificación de imaginación contiene y supone une modificación de neutralidad (he ahí uno de los problemas del claro deslinde). Sin perjuicio de querer amalgamar ambas modificaciones bajo una raíz común -pues no hay tal si no es transposición arquitectónica mediante- todo se complica diabólicamente tan pronto como leemos seriamente y de cerca el texto $\mathrm{n}^{0} 16$ de Hua XXIII. Propósito que puede asistir el extraordinario texto de Richir "Les structures complexes de l'imagination selon et au-delà de Husserl". pdf, Annales de Phénoménologie (2003) 90-141, www.annalesdephenomenologie.org). La lectura de este abismal manuscrito de Husserl, manuscrito en el que, como en muchos otros, surgen los abismos hiperbólicos que 
el suelo último de la fenomenología, con volverlo sombra, ¿sombra -inclusode inmanencia? Nunca. He ahí, precisamente, el recinto de Verdad -diría Michel Henry- en que el Genio Maligno no puede penetrar. El texto sobre esa inquietante, cuodlibetal neutralización que hemos citado más arriba, termina con un pasaje en el que Husserl, ya ebrio de neutralizaciones, por fin le pone freno a esta insensata hiperbolización de la neutralización, (y es que, ino puede haber Gegenbilder o Schattenbilder de todos y cada uno de los elementos de la concrescencia transcendental!) cerrándole así el paso, in extremis, al Genio Maligno, y recuperando la verdad, la originalidad, la univocidad última del ser de veras; y haciéndolo del hilo de ese "sólo una" con que empieza esta cita y que Husserl, consciente de la enorme importancia de lo que allí estaba en juego, subrayó como soldando el último resquicio de una caja de Pandora que acaso entreabrió más de la cuenta:

Sólo una ponibilidad dóxica les queda a las vivencias neutrales: la que les es inherente en cuanto datos de la conciencia inmanente del tiempo y las determina justo como conciencia modificada de un nóema modificado". ${ }^{87}$

Se abre aquí, consonando con este texto y esta problemática, un apasionante ámbito de explicitación mereológica maravillosamente balizado por la cuarta y última parte ("La estructura temporal de la mónada") de la ya citada obra de Agustín Serrano de Haro Fenomenología transcendental y ontología. A mi parecer, una de las claves estaría en el análisis mereológico de los trechos de temporalidad representificados (sobre todo en su parte reell), y que a veces arrojan teratologías hiperbólicas como, en Erste Philosophie II, la idea de una quasi-epojé (o de las dobles reducciones en general). Serrano de Haro, en los

las presentaciones doctrinales del propio Husserl ni siquiera conseguían del todo recubrir, pone de manifiesto que los quicios en que incide la pinza de la modificación de imaginación o puesta en imagen son mucho más profundos y sutiles, mucho menos a disposición de lo que pensábamos. Conscientes, repetimos, de que no se ha de confundir la modificación de neutralidad simple con la modificación de imaginación, añadiremos que la complejidad arquitectónica de la modificación de imaginación puede conducir a que, sin perjuicio de su fusión, acaben resultando, en ciertos casos, sencillamente indiscernibles. Ejemplo de ello es el sobrecogedor excurso por la figura infantil del "coco" que hace García Lorca en su memorable conferencia sobre las nanas o canciones de cuna. García Lorca esboza una interesantísima fenomenología de la "parecencia" del "coco", de su inminencia nunca cumplida, de su virtualidad, generadora (precisamente en virtud de su ausencia) de efectos. Así y todo, la figuración del "coco", por indeterminada que sea su representación (e imposible representificación), cae del lado (aperceptivo) de la imaginación y no de la phantasia. Trataré de volver sobre esa fenomenología de la parecencia apuntada por García Lorca en ulteriores trabajos.

${ }^{87}$ Ideas $I$, p. 272.

"Bloß eine doxische Setzbarkeit verbleibt auch den neutralen Erlebnissen: die zu ihnen als Daten des immanenten Zeitbewußtseins gehörige, sie eben als modifiziertes Bewußtsein von einem modifizierten Noema bestimmend". Hua III/1 261. 
últimos capítulos de la citada obra, ha ofrecido brillantísimos análisis, en relación con la conciencia interna del tiempo, de ciertos cursos de experiencia montados, como no puede ser de otro modo, sobre la experiencia del tiempo. Cursos de experiencia que lo son de síntesis a las que parece tener que abrir un "espacio" la conciencia interna del tiempo: "constituirlas" en el profundo sentido mereológico del término. Serrano de Haro examina, entre las páginas 544 y 550 de su Fenomenología transcendental y ontología dos casos de vivencias intencionales, naturalmente también temporales, constituidas por y desde la conciencia interna del tiempo: cursos de tiempo en el tiempo, cursos de experiencia en la experiencia ( $y$ no otra cosa quiere decirse cuando se alude a ciertos casos de esto mismo con el término Vergegenwärtigung, representificación). Se trata de los casos de síntesis judicativa y de síntesis imaginativa o representificación propia de la imaginación. Esos análisis de vida transcendental sintetizada en el interior de la vida transcendental de la conciencia interna del tiempo constituyen materiales analíticos valiosísimos para elaborar una descripción mereológica de la epojé hiperbólica en Richir y, por supuesto, de las "experiencias" (¿o habría que decir "inminencias de experiencia"?) a que aquélla pretende abrir.

Evidentemente, desde el enfoque que es el mío, yo insisto en la importancia de un tratamiento mereológico de la reducción. $Y$, del peso de dicha exigencia, en la importancia de buscarle una residencia mereológica al fenomenologizar. ¿Qué es, en la concreción transcendental, eso relativamente otro de la vida constituyente que es el fenomenologizar? Acaso una de las claves para dar respuesta satisfactoria a esta pregunta sea, partiendo de esa última parte de la obra de Serrano de Haro, tratar de ver cuál es la relación entre el fenomenologizar o la (meta)síntesis fenomenologizante y la síntesis longitudinal de la conciencia interna del tiempo en que se autoaparece el flujo como tal; ver, en suma, cuáles son los solapamientos de fondo y las diferencias, la raíz común (como acaso pareciera desprenderse de las últimas páginas del citado trabajo de A. Serano de Haro) -o la absoluta disparidad (cual es mi profunda convicción) - de sus incoaciones respectivas. 